Universidad de Lima

Facultad de Comunicación

Carrera de Comunicación

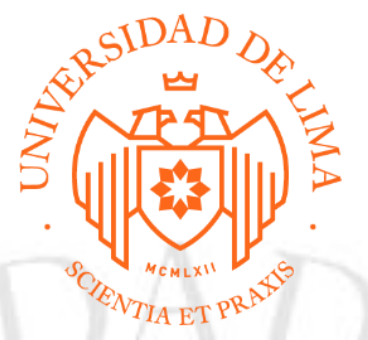

\title{
GESTIÓN DE CRISIS CORPORATIVA EN EL SECTOR AEROCOMERCIAL: CASO VIAJE LINDO AIRLINES
}

Trabajo de Suficiencia Profesional para optar el Título Profesional de Licenciado en Comunicación

LUIS MIGUEL MESTANZA RIVERA

Código 20100719

$$
\text { Lima - Perú }
$$

Octubre de 2019 


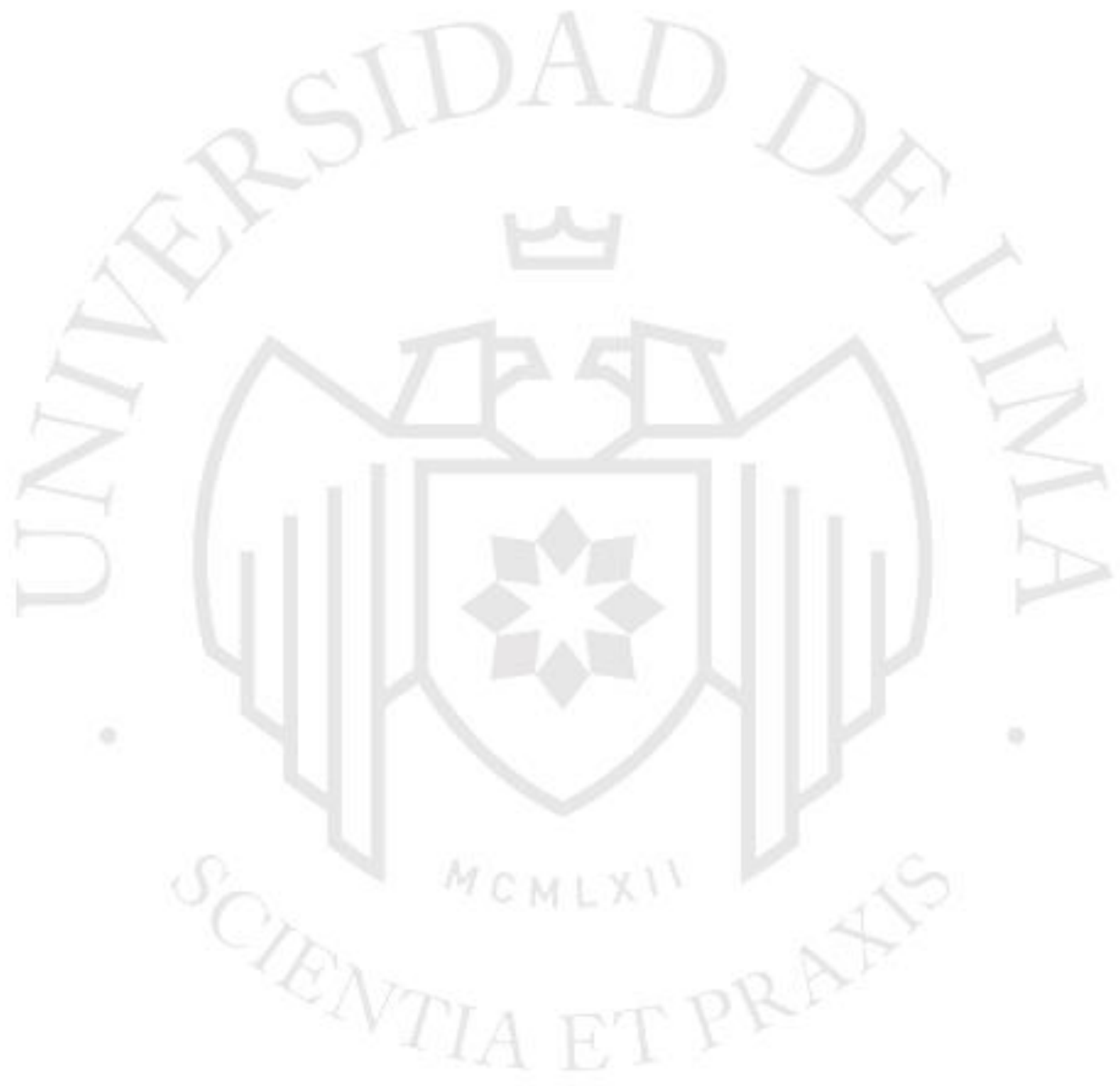


GESTIÓN DE CRISIS CORPORATIVA EN EL SECTOR AEROCOMERCIAL: CASO VIAJE LINDO AIRLINES 


\section{ÍNDICE}

RESUMEN

INTRODUCCIÓN............................................................................11

1.ANTECEDENTES DEL TRABAJO.........................................13

1.1 ¿Qué es una crisis corporativa? ..........................................13

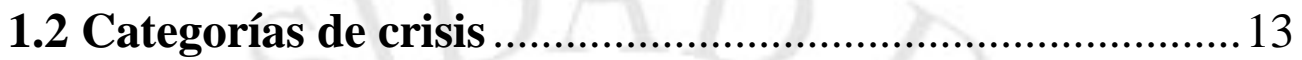

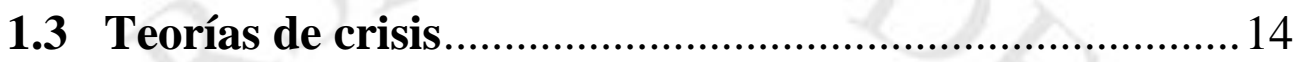

1.4 Casos de gestión de crisis corporativas...............................16

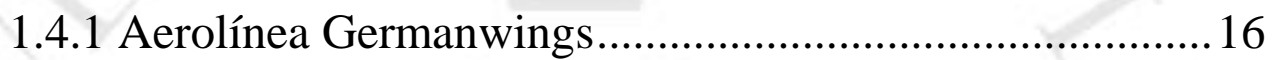

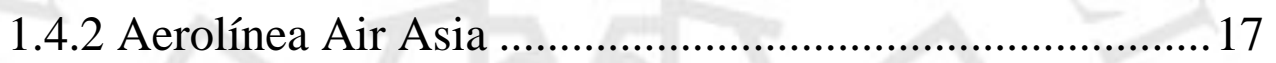

1.4.3 Aerolínea Air Algerie ......................................................19

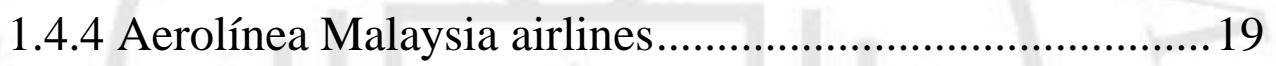

1.4.5 Aerolínea AirFrance ........................................................20

1.5 Las relaciones con los medios en situaciones de crisis .....21

1.5.1 ¿Qué le pide un periodista a un DIRCOM? .....................21

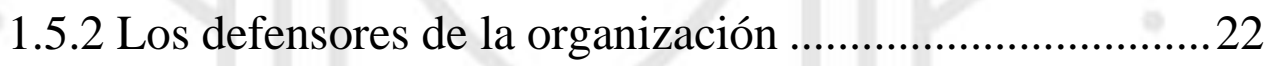

1.5.3 Los medios de comunicación y la agenda setting .............23

1.6 Efectos del internet en la gestión de crisis .........................23

1.7 La transparencia en la era de la hiperconectividad .........24

1.8 La etapa de prevención de una crisis ..................................24

1.9 La imagen como oportunidad de desarrollo .....................25

1.10 Análisis de la empresa Viaje Lindo Airlines ...................25

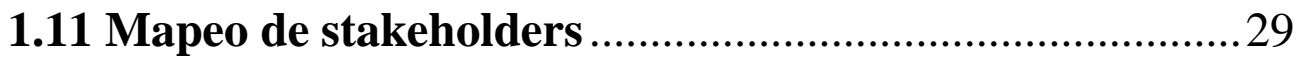

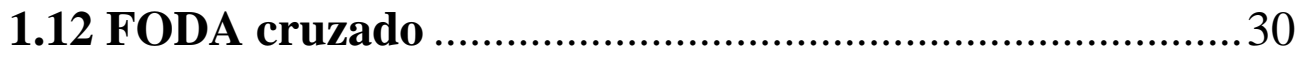

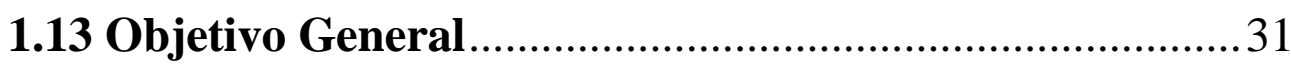

1.13.1 Objetivos específicos etapa crisis......................................31 
1.13.2 Objetivos específicos etapa post crisis

2. PROPUESTA DE COMUNICACIÓN 32

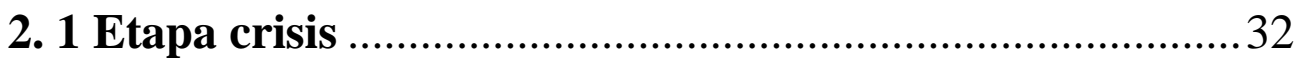

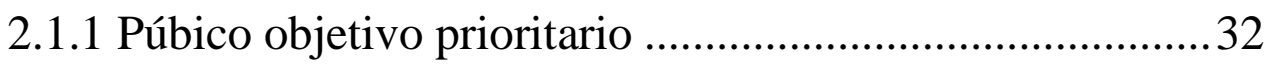

2.1.2 Rol de los integrantes del gabinete de crisis .....................32

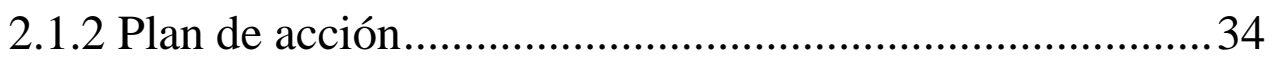

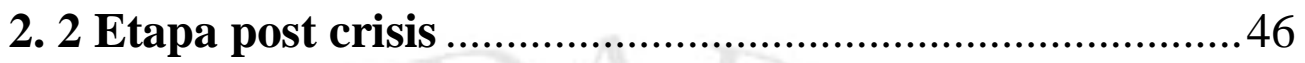

3. SUSTENTACIÓN .............................................................................58

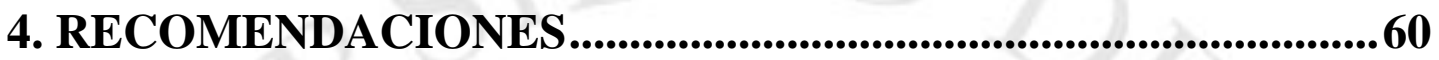

5. PRESUPUESTO POST- CRISIS ......................................................67

6. CRONOGRAMA .................................................................................67

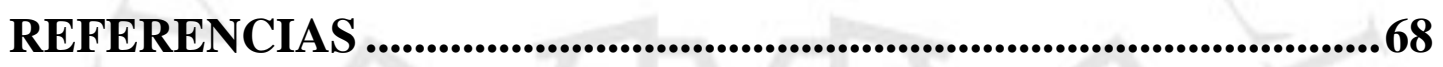


Dirección web de las piezas y producciones de comunicación parte del trabajo

Manual de crisis corporativa

https://drive.google.com/file/d/16e2U 0Hr7URytlnuBrYxb-

HqqXPT5lg/view?usp=sharing 


\section{ÍNDICE DE TABLAS}

Tabla 1. Tabla Foda cruzado.................................................... 30

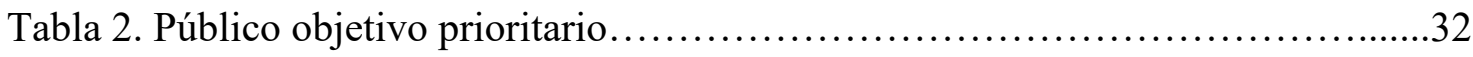

Tabla 3. Rol de los integrantes del gabinete de crisis............................... 33

Tabla 4. Plan de acción etapa crisis.......................................... 35 


\section{ÍNDICE DE FIGURAS}

Figura 1. 1. Public trust in organisational advocates............................22

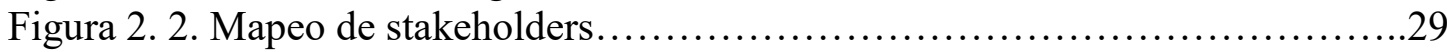

Figura 3.3. Perfil de la competencia.......................................65 


\section{RESUMEN}

La preocupación por gestionar los valores intangibles de las empresas responde a la necesidad de diferenciarse cada vez más y enfrentarse a la complejidad del entorno (interacciones). En ese sentido, y siguiendo con los objetivos de la empresa Viaje Lindo Airlines, el enfoque del Dircom resulta ser una alternativa eficiente para gestionar la actual crisis comunicacional.

Para ello se generará un plan de gestión de crisis a corto y mediano plazo enfocado en los distintos stakeholders de la organización, para después desarrollar estrategias de posicionamiento que reafirmen los atributos de la empresa. Cabe mencionar que se integrarán herramientas digitales para atender esta crisis corporativa.

Palabras claves: Sector aeronáutico, gestión de comunicación, crisis corporativa, comunicación preventiva, estrategias. 


\section{SUMMARY}

The concern to manage the intangible values of companies responds to the need to differentiate more and more and face the complexity of the environment (interactions). In that sense, and following the objectives of the company Viaje Lindo Airlines, the Dircom approach turns out to be an efficient alternative to manage the current communication crisis.

For this, a short and medium term crisis management plan will be generated, focused on the different stakeholders of the organization, and then develop positioning strategies that reaffirm the company's attributes. It's worth mentioning that digital tools will be integrated to address this corporate crisis.

Keywords: Aeronautical sector, communication management, corporate crisis, preventive communication, strategies. 


\section{INTRODUCCIÓN}

Está claro que hoy en día en el campo organizacional las empresas son más susceptibles de sufrir una crisis corporativa. No importa el sector en el que se desarrolla la actividad empresarial, finalmente esta puede afectar de forma negativa la imagen y reputación de la empresa frente a sus públicos.

Atrás quedaron los tiempos en donde las organizaciones tenían el dominio empresarial de lo público y las herramientas publicitarias. Ahora con la democratización de la tecnología, los usuarios obtienen un rol más activo donde exigen una comunicación más personalizada y transparente. En este contexto, la comunicación asume ser una variable de acción propia de la organización y deja de ser un elemento estético o propagandístico.

Este acontecimiento está generando que las acciones de comunicaciones en situaciones de crisis actúen de forma instantánea, además de generar espacios de diálogos confiables donde las personas encuentren puntos de conexión. Como mencionaba Cornado (como se cita en Diálogos con los DIRCOM: conceptualizaciones, casos y expertos, 2015) el objetivo que persigue la comunicación en una situación de crisis es "conseguir credibilidad en la organización como fuente de información y generar confianza, tanto en el conjunto de la opinión pública como en las autoridades y los medios de comunicación".

Cabe mencionar que la gestión de la comunicación en situaciones de crisis no empieza en la crisis en sí misma, sino en la fase de preparación. Para Losada (2018) esta fase se denomina NO(CRISIS): trabajar sobre lo que puede pasar alrededor de la empresa, confiando que nunca llegue a ocurrir. Para el autor este planteamiento empieza por programar un protocolo de actuación sistemático para ponerlo en marcha cuando se alcance un escenario de gravedad.

Dadas estas evidencias, nos encontramos frente a un escenario donde comunicar se ha tornado más difícil, pero también más relevante. Ahora las empresas construyen su reputación a partir de sus procesos de comunicación estratégicos y aplican enfoques, como las del Dircom, para gestionar sus valores intangibles.

Así, Joan Costa (2012) señala que: el Dircom es básicamente un estratega global que gestiona la comunicación empresarial y los valores intangibles de la empresa (p.2) Siguiendo con este pensamiento, el Dircom tendrá que desarrollar habilidades directivas, 
planificar y gestionar estrategias, dotar de sensibilidad los mensajes de alta gerencia, dirigir las comunicaciones y las relaciones con los stakeholders, velar por la responsabilidad de la imagen, la reputación y el posicionamiento corporativo, crear una cultura corporativa y fortalecer la propuesta de valor.

Bajo este enfoque, el presente trabajo de suficiencia profesional se basará en desarrollar un plan de gestión de crisis a corto y mediano plazo enfocado en los distintos stakeholders de la organización sin descuidar la gestión de sus valores intangibles ni la coyuntura por la cual la empresa está pasando. Aplicaremos una visión holística de la comunicación en donde se buscará integrar la comunicación institucional (relaciones corporativas, imagen corporativa, desarrollo corporativo), organizacional (cultura corporativa, comunicación interna) y mercadológica (branding, publicidad, promoción comercial) para crear valor a la organización y poder relacionarse con sus públicos. Para ello se empezará a desarrollar un plan de acción a corto plazo tomando el proceso Crisis \& Emergency Risk Communication (2015), añadiendo herramientas 2.0. Para después realizar el manual de crisis desde una perspectiva preventiva.

Sin lugar a duda esta estrategia de comunicación será un aporte muy importante para cumplir el objetivo planteado: salvaguardar la reputación y mantener el posicionamiento de la compañía. En este trabajo se explicará cómo desde la perspectiva de la comunicación se conseguirá aportar a dicho objetivo. 


\section{ANTECEDENTES DEL TRABAJO}

\section{1 ¿Qué es una crisis corporativa?}

La crisis es una situación con trascendencia e importancia para el público que compromete la reputación, capacidades y credibilidad de la empresa (Cervera 2004). Es también entendida como la gestión de cada organización para determinar si fue un proceso de aprendizaje o solo una salida de paso. Como afirma González (1998) “mientras que para algunos la gestión de crisis tan sólo consiste en una serie de medidas y decisiones más o menos urgentes que se han de tomar ante la existencia de un problema, para otros la gestión de crisis comienza mucho antes e incluye medidas de prevención y planificación (existiendo, por tanto, gestión de crisis aun cuando nunca llegue a darse una situación de ese tipo).

Por otro lado, para la Real Academia española la definición de crisis no debe entenderse siempre como algo negativo, sino más bien, hace referencia a un proceso de cambio.

\subsection{Categorías de crisis}

Según Rojas (2014) existen los tipos de crisis según las posibilidades de preverlas, sus consecuencias y su forma o evolución.

\section{a) Según la previsión}

Crisis predecible: Es aquella que se puede prevenir ya que existen precedentes que anuncian el riesgo.

Crisis imprevisible: Difícil de prever, son situaciones no deseadas.

\section{b) Según consecuencias}

Crisis leve: Situaciones de corta duración, previstas y detectadas con antelación. El impacto es mínimo y la empresa está preparada para enfrentarla. 
Crisis aguda: Produce un enorme impacto negativo en la repercusión pública, por lo que se requiere una buena preparación previa.

\section{c) Según forma}

Crisis naciente: Son situaciones que se pueden prever con la percepción de tendencias, rumores. Existe tiempo para analizar las causas y darle solución.

Crisis súbita: Suele ser de carácter agudo, no permite analizar las causas ni planear un plan de acción. Salvo que la empresa haya desarrollado previamente un plan de crisis preventivo.

Crisis sostenida: Son duraderas y sostenidas por los medios de comunicación.

\subsection{Teorías de crisis}

\section{A) Anticipatory model of crisis management (AMCM) - Olaniran y Williams (2000)}

Los autores aseguran que no hay otro modo de reaccionar adecuadamente a una crisis que no sea una excelente preparación, bajo dos conceptos: promulgación (reconocer la idea de que cuando las personas actúan de una forma determinada, ocurren consecuencias donde se tienen que anticipar oportunidades, amenazas, debilidades. Expectativas (suposiciones que la gente hace sobre ciertos acontecimientos), la idea es conocerlas para que no se agrave o exista una crisis.

\section{B) Image restoration theory (IRT) - Benoit (1994)}

Identifica 5 estrategias de reparación de imagen:

1)Negación: negar los hechos o trasladar la responsabilidad a otros.

2)Eludir responsabilidades

3)Minimizar la ofensa: desempeño histórico de la empresa

4)Acción correctiva: cuando la empresa admite el problema y se ofrece para arreglar el daño causado o dar pasos para que no se vuelva a repetir. 
5)Disculpa - mortificación: admiten su comportamiento, se disculpa, piden perdón y muestran su deseo de que la gente no les juzgue tan severamente.

\section{C) Situational crisis communication theory - Coombs (2007)}

Comprender la situación y su potencial gravedad para la organización, algo que Coombs asocia directamente con la amenaza a su reputación. Esta amenaza contempla:

1)Responsabilidad inicial de la crisis:

Presentable cluster (elevada responsabilidad de la empresa y una amenaza severa para su reputación).

2) Historia de la crisis: crisis en el pasado se le atribuye mayor responsabilidad en la crisis.

3) Reputación previa: una organización que trato mal a sus públicos en el pasado se atribuye mayor responsabilidad en la crisis y sufre daño a su reputación.

Coombs enfatiza el poder de las emociones en todo el proceso de gestión y reacción por parte de la organización y de sus públicos. SCCT incorpora reacciones estratégicas de respuestas primarias y secundarias (negación, disminución y reconstrucción)

\section{D) Crisis and emergency risk communication as an integrative model (CERC)}

Desarrollado por expertos en comunicación del center for deseae prevention and control de EE. UU

1) Fase pre crisis: en la que se encuentra la diseminación de alertas y mensajes de riesgo.

2) Initial event: primera fase de reacción, la idea es hablar públicamente para hacer entender a los ciudadanos las circunstancias, las consecuencias y los resultados a partir de la información disponible.

3)Maintenance: conjunto de acciones que realizar cuando la crisis esté en marcha, reducir las incertidumbres y aportar seguridades. 
4) Resolution: fase centrada en informar sobre la recuperación de la situación inicial y la reconstrucción. Momento de responder a las responsabilidades de la crisis, así como posibles riegos en el futuro y la forma de afrontarlos.

5)Evaluación: analizar el plan desarrollado, con el objetivo de que este análisis sirva para modificar todo aquello que no haya funcionado adecuadamente.

\section{E) Social mediated crisis communication (SMCC) - Austin, Liu y Jin (2011)}

Esta propuesta incorpora la parte de responsabilidad de los actores digitales en el desarrollo de las crisis. En conclusión, el modelo SMCC describe la interacción entre una organización en crisis y tres tipos de públicos que producen y consumen información antes, durante y después de la crisis: los influencers, los seguidores de las redes sociales y los medios de comunicación social inactivos (consumen indirectamente la información de la crisis de los creadores de medios sociales influyentes a través del boca a boca

1) Origen de la crisis

2) Tipo de crisis

3) Infraestructura organizacional

4) Estrategias de mensajes

5) Forma del mensaje

\subsection{Casos de gestión de crisis corporativas}

Los siguientes casos de gestión de crisis corporativas han sido tomados del informe: Catástrofes aéreas y reputación Un análisis de la gestión de crisis en los últimos 15 años de la consultora Logic Activity (2015). Para nosotros es fundamental conocer todas estas experiencias, ya que serán casos referenciales antes de empezar el plan de crisis.

\subsubsection{Aerolínea Germanwings}

El 24 de Marzo del 2015 el vuelo 4U9525 con trayecto entre Barcelona y Dusseldorf de la aerolínea Germanwings se estrelló en los Alpes Franceses de Provenza dejando 150 víctimas. La causa del accidente se debió a que el primer oficial (copiloto) estrelló el avión para suicidarse, ya que tenía problemas mentales. (El país, 2015) 
Acciones llevadas por la compañía:

-Tardaron menos de una hora_en reaccionar a través de sus canales corporativos.

-El CEO de Lufthansa lanzó un mensaje en vídeo apenas 24 horas después del accidente.

- El mismo día de la tragedia, los CEOs de Lufthansa y Germanwings, Casten Spohr y Tomas Winkelman, realizaron ruedas de prensa para informar sobre el accidente y se mostraron abierto a todo tipo de preguntas por parte de los medios de comunicación.

- Lufthansa puso a disposición de los familiares de las víctimas dos vuelos para acercarles al lugar de la tragedia.

-Lufthansa ofreció a las familias una primera indemnización de 50.000 euros por víctima, una compensación compatible con futuras reclamaciones a las compañías aseguradoras.

- Logo de Germanwings teñido de negro y retirada del número de vuelo.

-3 días después de la catástrofe Lufthansa anuncia "la regla de dos": en la cabina siempre deberán estar dos personas como mínimo. Con efecto en todas las compañías del grupo.

-La compañía aérea utilizó Twitter como canal para difundir sus comunicados de prensa. \#indeepsorrow.

-Lufthansa usó las redes sociales para solidarizarse con las víctimas del siniestro y con sus familiares, cambiando las cuentas a tonos grises de luto.

- El CEO de Lufthansa lanzó un mensaje en vídeo apenas 24 horas después del accidente.

-Lufthansa se hace eco de la presión que sufren los familiares de las víctimas por parte de los medios de comunicación, sin embargo, tarda 4 días en difundir los teléfonos de atención a los medios.

-Germanwings será absorbida por Eurowings, la decisión fue tomada en diciembre de 2014, antes del accidente.

\subsubsection{Aerolínea Air Asia}

El 28 de diciembre del 2014 el vuelo QZ8501 con trayecto de Surabaya y Singapur de la aerolínea Air Asia se estrelló en aguas de la isla de Borneo con 162 personas a bordo. La causa del accidente se debió a una falla mecánica. (El Mundo, 2014) 
Acciones llevadas por la compañía:

-En total la compañía emitió más de 58 notas de prensa sobre el accidente. Al principio con frecuencia diaria.

-Call center de información para familiares de pasajeros y tripulación, un centro de emergencias en los aeropuertos de salida y llegada prevista del vuelo, y teléfonos de contacto para los países de procedencia del pasaje (Singapur, Corea, Malasia e Indonesia).

- Fernándes, fundador de la compañía, viajó inmediatamente a Surabaya, punto de partida del vuelo desaparecido y origen de la mayoría de los pasajeros a bordo.

- Presencia en el aeropuerto de diversas autoridades y ruedas de prensa en distintas localidades, algunas emitidas por televisión.

- Días más tarde aparecía en la web el apartado "Update on QZ8501 \#togetherwestand" con información actualizada. A día de hoy la información sobre el accidente está en un enlace en la parte inferior de la web.

-Fernandes envió una carta a todos los clientes que alguna vez usaron los servicios de Air Asia en la que transmitía los duros momentos por los que pasaba la aerolínea y agradeció el apoyo a quienes, pese al accidente, les seguían eligiendo. Además, prometía mejoras en sus productos y servicios.

-El fundador de Air Asia estuvo muy activo en Twitter, con mensajes dirigidos a familiares de las víctimas: "Ésta es mi peor pesadilla".

- Air Asia tiene perfil oficial en varias redes sociales: Twitter, Facebook, YouTube, Instagram y Pinterest; en todos ellos se cambió el logotipo rojo por uno gris.

- Las cuentas en los medios sociales se emplearon para difundir información sobre el accidente, para publicar novedades y en el caso de Facebook para contestar preguntas.

-Twitter fue el canal elegido para difundir la confirmación de que se había perdido el contacto con el avión.

- En los primeros días se utilizaron los hashtags \#staystrong y \#QZ8501. Posteriormente cuando se confirmó la existencia de víctimas se pasó a \#togetherwestand, también en las cabeceras de los canales de Twitter y de Facebook de la compañía resaltando el "we". Actualmente esta cabecera ya no aparece. 


\subsubsection{Aerolínea Air Algerie}

El 24 de Julio del 2014 el vuelo AH5017 con trayecto de Uagadugo y Argel de la aerolínea Air Algerie se estrelló en el sur de la ciudad Goss con 116 personas a bordo. La causa del accidente se debió al mal clima. (El Mundo, 2014)

Acciones llevadas por la compañía:

-La compañía emitió 16 comunicados.

- El director general de la compañía se desplazó a Mali donde pronunció unas palabras y dejó en marcha un teléfono de atención a familiares en Argelia y Francia.

-Declaración a medios del responsable de relaciones institucionales sin aceptar preguntas.

-Air Algerie publicó en una de sus cuentas de Twitter 5 tuits relacionados con el accidente y retuitearon 19 mensajes de condolencias entre el 24 y el 28 de julio.

- En Facebook publicaron una única entrada el 26 de julio expresando su tristeza y sus condolencias a las familias y allegados.

- Remitieron a su web para más información. Los comunicados se han eliminado y no hay ninguna referencia al accidente.

\subsubsection{Aerolínea Malaysia airlines}

El 08 de marzo del 2014 el vuelo MH370 con trayecto de Kuala a Pekín de la aerolínea Malaysia Airlines desapareció en el océano Índico con 239 personas a bordo. La causa del accidente se desconoce hasta la actualidad. (El Comercio, 2019)

Acciones llevadas por la compañía:

-La aerolínea ha emitido un total de 72 comunicados.

- Puso un teléfono y direcciones de correo electrónico a disposición de los afectados y ese mismo día, más tarde, comunicó otro teléfono para medios de comunicación.

- Habilitó un dark site dentro de su web con información actualizada del accidente.

- El portavoz inicial de la compañía fue su director general quien emitió una nota de prensa a la hora de conocerse el suceso.

- La rueda de prensa se dio al siguiente de la desaparición. 
- Organizaron un equipo formado por más de 250 personas para la atención a las víctimas con psicólogos y enviaron a más de 100 empleados y personal de atención a Beijing.

- Se realizaron varios encuentros con familiares en Malasia y en China.

-La compañía asumió los costes de desplazamiento, manutención y alojamiento.

-Durante 2 meses la compañía pagó los hoteles a los familiares de las víctimas del accidente.

- Retiró los códigos de vuelo MH370 y MH371 como muestra de respeto.

- Durante un año tuvo abiertos 7 centros de asistencia y apoyo a familiares de las víctimas. -Cambio de la foto de portada en Facebook, en total fueron 9 mensajes en Facebook el día de la desaparición. En Twitter fueron 7 mensajes del día de la desaparición, utilizaron la etiqueta \#MASAlert, sin embargo \#MH370 y \#MalaysiaAirlines se convirtieron en trending topics.

- Actualización de medios sociales entre 3 y 4 veces al día en los primeros días.

- Publicación en Instagram de foto conmemorativa.

- 16 días después de la desaparición del vuelo la compañía contactó con los familiares de los pasajeros a través de SMS para comunicarles que daban el avión por siniestrado en el Océano Índico y a todos los ocupantes por fallecidos. El CEO de la compañía explicó que la única motivación de informar mediante esta vía a los familiares era garantizar que las familias recibían la trágica noticia antes que el resto del mundo. Hay que mencionar que esta última acción fue percibida como una acción ofensiva por parte de los familiares, tanto así que se pidieron la dimisión del CEO de la organización.

\subsubsection{Aerolínea AirFrance}

El 01 de junio del 2009 el vuelo AFF447 con trayecto de Río a París de la aerolínea AirFrance desapareció en el océano Atlántico con 228 personas a bordo. La causa del accidente fue una negligencia de la tripulación. (Clarín, 2019)

Acciones llevadas por la compañía:

-Emitieron un total de 28 comunicados en inglés, francés y portugués entre el día del accidente y julio de 2014

- El día del accidente, la compañía emitió 6 comunicados (el primer comunicado lo emitieron 2 horas después del accidente). 
-Rueda de prensa del director general de Air France, Pierre-Henri Gourgeon, el mismo día.

-Habilitaron 3 teléfonos para familiares. Primero Francia e internacional y luego Brasil. -El mismo día del accidente, informaron de que varios especialistas en atención médica y psicológica se establecieron en los aeropuertos de Paris-Charles de Gaulle y Río de Janeiro.

- Reunieron a los familiares en zonas reservada de los aeropuertos.

- Crearon un área especial en su web para la publicación de comunicados y otra para información más amplia (compensaciones, planes de vuelo, mantenimiento, etc.) -Proporcionaron alojamiento gratuito a familiares en París y en Río.

-Construyeron 2 memoriales.

- Adelantaron 17.500 euros por víctima.

-Eliminaron ese número de vuelo.

-5 días después del accidente anunciaron que habían acelerado el recambio de los sensores de velocidad de sus aviones A330 y A340, ante la posibilidad de que éstos pudieran haber tenido algo que ver en el accidente.

En esta crisis se puede apreciar que las redes sociales no tenían el impacto ni la presencia que hoy en día cuentan.

\subsection{Las relaciones con los medios en situaciones de crisis}

Los programas de relaciones con los medios casi siempre incluyen una estrategia de prensa en especial en situaciones de crisis. Para ello el Dircom dispone de diversos objetivos de producción y técnicas bajo este contexto. Entre las principales encontramos: Emitir un comunicado de prensa, elaborar un dosier de prensa, organizar conferencias de prensa, definir un portavoz, mantener una sala de prensa virtual, prever encuentros exclusivos con algunos periodistas.

\subsection{1 ¿Qué le pide un periodista a un DIRCOM?}

En el informe de la relación dircom- periodistas (2012) publicado por la Asociación de directivos de comunicación se precisó la importancia de mejorar el conocimiento entre los periodistas y el dircom, así como las vías para fortalecer sus relaciones. 
Entre las peticiones se destaca:

- No mentirle al periodista, ya que nunca perdona el engaño.

- Brindarle información con un enfoque relevante.

- Contactarlo regularmente con el fin de construir una relación profesional entre ambos.

- Respetar las dinámicas de su trabajo: plazos, tiempos, prisas, etc.

- Enviarle información exclusiva y no tanta información masiva.

- No clasificar su labor en función de los medios en los que trabaja (uno nunca sabe cuál será su próximo destino)

\subsubsection{Los defensores de la organización}

Los profesionales de la comunicación y relaciones públicas no son las únicas personas que defienden a una organización en una situación de crisis. Según el informe de la European Communication monitor (2019) existen expertos externos a la empresa tales como los consumidores, clientes, fans o activistas que juegan un rol decisivo (hasta lovemark) al momento de una situación adversa. Ahora la confianza del público está puesta en expertos académicos y personas externas (como uno mismo).

Public trust in organisational advocates: External experts, supporters, top managers and employees are more trusted than communication practitioners

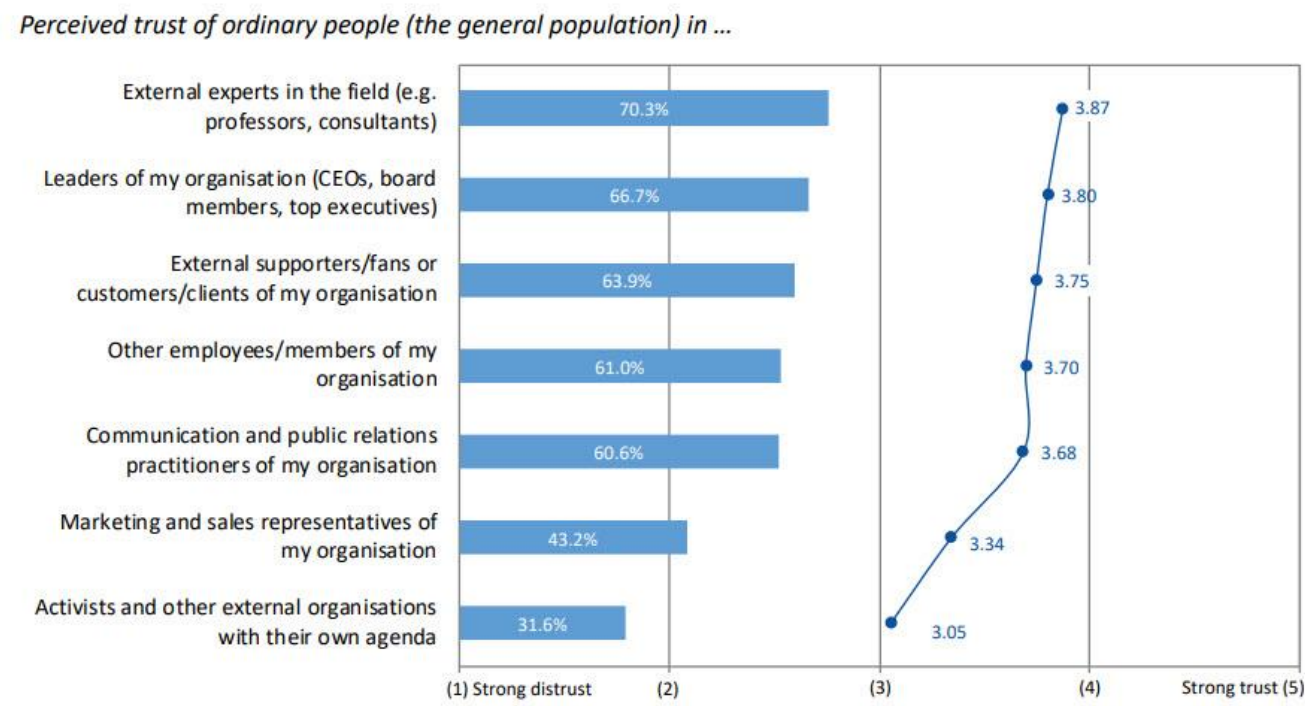

Fuente: European Communication monitor (2019). Recuperado de: http://www.communicationmonitor.eu/ 
Es importante enfocarse en estos expertos externos, ya que sus opiniones influyen en el pensamiento de las personas e incluso en algunos casos llegan a tener cobertura en medios tradicionales y digitales.

\subsubsection{Los medios de comunicación y la agenda setting}

Los medios de comunicación según Walter Lippman (2003) tienen la capacidad de guiar nuestra atención hacia ciertos temas que publican. Y es que los medios al tener esa capacidad nos imponen la pauta que influyen en la agenda mediática. En esta disputa por establecer las características sobre la crisis en los medios, se tendrá que considerar a los protagonistas, antagonistas y audiencias para determinar la situación. El primero siempre buscará disminuir los daños y obtener beneficios por la situación, mientras que el segundo, tratará de dañarla. Siempre las audiencias serán buscadas para que se sumen a una posición y apoyen positiva o negativamente a la crisis. Los medios de comunicación tomarán una postura sobre el tema y se evidenciará en cómo presentan la información en sus espacios de noticias.

\subsection{Efectos del internet en la gestión de crisis}

La crisis en los medios sociales es definida por Coombs y Holladay (2012, p. 409) como una amenaza públicamente visible de una crisis que culpa la organización por un comportamiento antiético o irresponsable. Para Coombs (2012) es una preocupación que surge en los medios sociales o es amplificada por los medios sociales y que influye negativamente en la cobertura de los medios tradicionales, las operaciones de la organización, o amenaza las finanzas de la organización.

Estos efectos del internet en situaciones de crisis se pueden apreciar con el surgimiento de rumores y prosumidores. Este último tienen la capacidad de ejercer daño significativo a la reputación de la empresa si en verdad lo desea hacer. Otro tipo de efecto se relaciona con el alcance, ya que aumenta el reconocimiento del problema y la vuelve más vulnerable. 


\subsection{La transparencia en la era de la hiperconectividad}

Vivimos en tiempos donde la tecnología permite que las personas se relacionen con las marcas a un nivel más próximo. Esta nueva concepción implica mayor transparencia en la forma como las empresas actúan y se comunican. Atrás quedaron los tiempos donde las organizaciones tenían el dominio empresarial de lo público. Ahora con la accesibilidad y democratización de la tecnología las personas asumen un rol fiscalizador y demandan comportamientos éticos y sostenibles.

Sin lugar alguna las redes sociales se han convertido en espacios interactivos donde las organizaciones ponen mayor énfasis para participar y tener mayor presencia en los medios. Para Luis Picazo Martines, coach de comunicación, las empresas son conversaciones, donde su gestión se basará en conversaciones internas y externas con interlocutores cuya relevancia estará vinculada a la confianza que depositen en la organización. (2018, p.22)

Hay que mencionar que la gestión de la comunicación en situaciones de crisis no debe descansar, precisamente, en las tecnologías. La esencia no se encuentra ahí. El centro de gravedad se halla fundamentalmente en la dimensión humana presente en todas estas situaciones, en la materia invisible que envuelve las relaciones humanas. (2018, p.26)

\subsection{La etapa de prevención de una crisis}

Cabe mencionar que la gestión de la comunicación en situaciones de crisis no empieza en la crisis en sí misma, sino en la fase de preparación. Para Losada (2018) esta fase se denomina NO(CRISIS): trabajar sobre lo que puede pasar alrededor de la empresa, confiando que nunca llegue a ocurrir. Para el autor este planteamiento empieza por programar un protocolo de actuación sistemático para ponerlo en marcha cuando se alcance un escenario de gravedad. En el caso de la aerolínea se tienen que prever los siguientes problemas:

- Accidente o desastre aéreo

- Avión retrasado/ extraviado 
- Interferencia ilícita

- Incidentes

- Turbulencia severa en aire

- Desastres naturales

- Desastres causados por el hombre

- Disturbios civiles

- Actos de guerra

- Cualquier interrupción significativa de la operación

\subsection{La imagen como oportunidad de desarrollo}

Entre los autores que afirman que la imagen es un recurso más de la organización para llegar a sus públicos, se encuentra San Nicolas y Contreras (2002) quien menciona que la imagen corporativa es un instrumento de gestión de las empresas e instituciones para representar todos sus atributos o facultades competitivas. No obstante, las investigaciones en el campo de la percepción, la cognición, las actitudes y la comunicación llevaron a considerar a los públicos como "sujetos creadores". En donde la imagen no es una cuestión de emisión, sino de recepción (Kapferer, 1992). Así, Costa (2001) señala que la imagen de una empresa es un efecto de causas diversas: percepciones, inducciones, experiencias, sensaciones, emociones y vivencias de los individuos, que de un modo $u$ otro - directamente o indirectamente - son asociadas entre sí y con la empresa. Asimismo, advierte que la imagen no es un recurso de urgencia para activar las ventas, ni es un auxilio inmediato para una promoción comercial, ni mucho menos un mecanismo para conseguir resultados medibles en el corto plazo. La imagen es una oportunidad de desarrollo para que las empresas puedan destacar su identidad corporativa, definir el sentido de la cultura organizacional, construir su personalidad, atraer a los mejores especialistas, evitar situaciones de crisis, impulsar nuevos productos o servicios, reducir los mensajes involuntarios, atraer a los clientes y fidelizarlos. Sin duda oportunidades que en siglo XXI favorecerán a la acumulación de prestigio y reputación.

\subsection{Análisis de la empresa Viaje Lindo Airlines}

- Es una aerolínea tradicional que opera en el mercado peruano desde 1995.

- Opera 8 rutas nacionales y su centro de operaciones es el Aeropuerto Internacional Jorge Chávez. 
- El boom del low cost está afectando las operaciones de Viaje Lindo.

-Su slogan traduce su promesa de marca: Seguridad y puntualidad a un mejor precio

-Desde sus inicios la empresa sostiene que sus aeronaves pasan por un riguroso control y mantenimiento.

- Viaje Lindo es la aerolínea con menos retrasos en minutos a nivel nacional.

- La empresa cuenta con un área de comunicaciones que ha tenido diversos cambios en su dirección.

-No tienen actualizado sus encuestas de clima laboral ni cuentan con un programa de incentivos para sus colaboradores.

- Sus canales de comunicación interna son: intranet, grupos de facebook y whatsapp.

- Sus canales de comunicación externa son: Página web, Fanpage, Twitter, Instagram y Linkedin.

-Poseen flota moderna que reduce la turbulencia, además de generar reducción de combustible y emisiones de $\mathrm{CO} 2$.

-Tienen planeado realizar más intervenciones sobre el medio ambiente entre sus públicos internos y externos.

- Se vive una cultura de aporte al medio ambiente donde los colaboradores participan de forma voluntaria.

-Entre sus valores está la seguridad y la puntualidad.

A continuación, se aplicará el test de Joan Costa "Las herramientas de gestión" (2012) para evaluar los dispositivos presentes en la empresa. El objetivo de este modelo de análisis es verificar punto por punto, los principales elementos de que se dispone en la empresa para la gestión integrada de acciones y comunicaciones.

\section{Comunicación institucional}

La empresa no dispone de un plan sistemático para el desarrollo de las relaciones con accionistas, instituciones, proveedores, es decir, públicos estratégicos.

\section{Comunicación organizacional}

No posee es un sistema de comunicación interna con su política de comunicación, sus soportes, contenidos y un sistema de circulación de la información.

\section{Identidad Visual}


La empresa no ha realizado cambios en su identidad visual.

\section{Gestión de marca}

La empresa no dispone de una política estructurada de marcas ni realiza acciones de branding.

\section{Comunicación de marketing}

La empresa no ha desarrollado un plan sistemático que integre la comunicación de la identidad/imagen y planes de marketing.

\section{Arquitectura corporativa}

La empresa no ha desarrollado una política de imagen en las oficinas o centros de atención. Tampoco evidencia algún tipo de merchandising propio que responda a sus necesidades específicas.

\section{Auditoría de imagen}

Si bien la empresa no ha realizado una auditoría estratégica global de la imagen, si se ha intentado hacer una de clima laboral (imagen interna). De esta iniciativa se llegó a la conclusión que la empresa tiene una cultura corporativa débil.

\section{Plan integral de comunicación}

La empresa no dispone de un plan en coordinación con el plan estratégico general, que incluya los objetivos de las diferentes direcciones y la comunicación institucional.

\section{Código deontológico}

La empresa no cuenta con un código deontológico.

\section{Responsabilidad social empresarial}

La empresa por tercer año consecutivo ha elaborado el reporte GRI. Esto refleja su cultura de aporte al medio ambiente (impacto medioambiental). 


\section{TICS}

Sus canales de comunicación interna son: intranet, grupos de facebook y whatsapp. Mientras que sus canales de comunicación externa son: Página web, Fanpage, Twitter, Instagram y Linkedin. Actualmente cuentan con una app.

\section{Gabinete de crisis}

La empresa si dispone de un gabinete de crisis solo que de los 7 miembros que solían ser solo queda 1. Sus reemplazos desconocían la existencia del gabinete.

Problema del negocio: ausencia de protocolos ante situaciones de crisis, no cuenta con un área de comunicación sólida, colaboradores desinformados, proliferación de rumores con respecto a las condiciones laborales de la empresa, aparición de haters con ánimos de enfrentarse a la empresa, crisis de comunicación a nivel online y offline. 


\subsection{Mapeo de stakeholders}

Bajo la Matriz de poder/ interés de Mendelow (1991) vamos a identificar a los stakeholders que precisamos trabajar de la mano en el plan de gestión de crisis.

\begin{tabular}{|c|c|c|}
\hline & Bajo & Alto \\
\hline • & $\begin{array}{l}\text { COMPETENCIA } \\
\text { Latam Airlines } \\
\text { Viva Airlines } \\
\text { Peruvian airline } \\
\text { Avianca Perú } \\
\text { Sky Perú } \\
\text { Star Perú } \\
\text { Atsa } \\
\text { Musoq } \\
\text { PROVEEEORES } \\
\text { Talma y Alteliza } \\
\text { (limpiezza de cabina) } \\
\text { APV \& Catering } \\
\text { (abastecimiento de comida) } \\
\text { Exxon Mobil } \\
\text { (combustible) } \\
\text { Peruvian Handling S.A } \\
\text { (servicio exterior del avión }\end{array}$ & $\begin{array}{l}\text { ONG } \\
\text { Perú } 2021 \\
\text { Prisma } \\
\text { SPDA } \\
\text { APECO }\end{array}$ \\
\hline & (Minimo esfuerzo) & (Mantener informados) \\
\hline 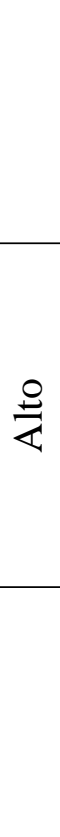 & $\begin{array}{l}\text { CLIENTES FRECUENTES } \\
\text { Clientes prime } \\
\text { Clientes básicos } \\
\text { ACCIONISTAS } \\
\text { Inversores institucionales } \\
\text { Accionistas minoritarios } \\
\text { Obligacionistas } \\
\text { Bonistas Titulares de preferentes } \\
\text { INVERSTONISTAS } \\
\text { Grupo de inversionistas }\end{array}$ & 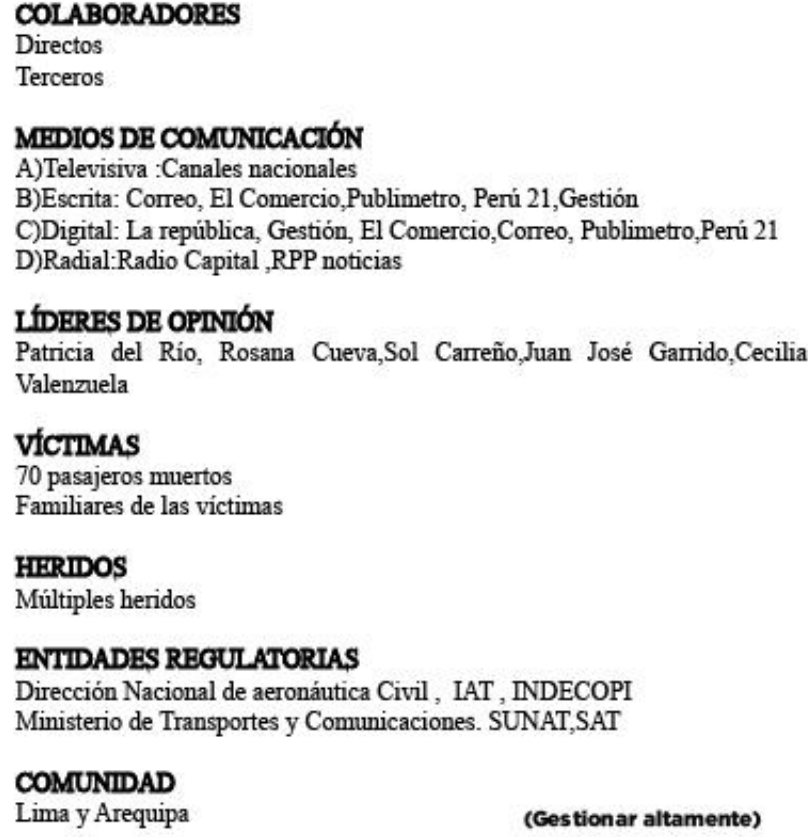 \\
\hline
\end{tabular}

(Elaboración propia) 


\subsection{FODA cruzado}

Esta herramienta nos sirve para conocer la situación real en que se encuentra la empresa, y planear una estrategia a futuro. Analizando sus características internas (Debilidades y Fortalezas) y su situación externa (Amenazas y Oportunidades) en una matriz cuadrada.

\begin{tabular}{|c|c|c|}
\hline & $\begin{array}{l}\text { Fortaleza } \\
\text { F1. Trayectoria de } 14 \text { años en } \\
\text { el mercado. } \\
\text { F.2 Posicionada como una } \\
\text { aerolínea puntual en rutas } \\
\text { nacionales y de carácter } \\
\text { segura. } \\
\text { F3. Cultura orientada al } \\
\text { aporte del medio ambiente. } \\
\text { F.4 Posee diversos premios y } \\
\text { reconocimientos ambientales. } \\
\text { F5. Disponen de medios } \\
\text { compartidos y propios para la } \\
\text { distribución de sus } \\
\text { contenidos. }\end{array}$ & $\begin{array}{l}\text { Debilidades } \\
\text { D1. Personal desinformado } \\
\text { D2. Alto nivel de rotación en } \\
\text { el área de comunicación. } \\
\text { D3. Los colaboradores se } \\
\text { sienten desmotivados. } \\
\text { D4. Descontrol de los canales } \\
\text { internos de la empresa. } \\
\text { D5. Mala gestión de crisis }\end{array}$ \\
\hline $\begin{array}{l}\text { Oportunidades } \\
\text { O1. Aprovechar las relaciones } \\
\text { públicas con la prensa } \\
\text { O2. Gestionar herramientas } \\
\text { digitales para enfrentar la crisis } \\
\text { O3. La prevención como una } \\
\text { guía de crisis } \\
\text { O4. Era de la transparencia } \\
\text { O.5 La imagen es una } \\
\text { oportunidad de desarrollo para } \\
\text { las empresas }\end{array}$ & $\begin{array}{l}\text { Estrategias } \\
\text { (O3, F2) Posicionar la } \\
\text { empresa como una aerolínea } \\
\text { que se preocupa por el } \\
\text { cuidado del medio ambiente. } \\
\text { (O4.F5) Informar a nuestros } \\
\text { stakeholders sobre la empresa } \\
\text { por nuestros medios propios. }\end{array}$ & $\begin{array}{l}\text { Estrategias } \\
\text { (O5. D3) Involucrar a los } \\
\text { colaboradores con la } \\
\text { trayectoria de la empresa para } \\
\text { crear un sentido de } \\
\text { pertenencia. }\end{array}$ \\
\hline $\begin{array}{l}\text { Amenazas } \\
\text { A1. Crisis corporativa } \\
\text { inesperadas } \\
\text { A2. Surgimiento de rumores y } \\
\text { su proliferación } \\
\text { A.3 Cambios en las necesidades } \\
\text { de los Stakeholders } \\
\text { A4. La aparición del ciudadano } \\
\text { fiscalizador y prosumidor }\end{array}$ & $\begin{array}{l}\text { Estrategias } \\
\text { (A4, F2) Organizar } \\
\text { actividades en donde se } \\
\text { posicione los atributos } \\
\text { principales de la empresa }\end{array}$ & $\begin{array}{l}\text { Estrategias } \\
\text { (D5, A2) Desarrollar políticas } \\
\text { de prevención que tengan } \\
\text { como eje la transparencia, la } \\
\text { accesibilidad y la difusión. }\end{array}$ \\
\hline
\end{tabular}




\subsection{Objetivo General}

Salvaguardar la reputación y mantener el posicionamiento de la compañía.

\subsubsection{Objetivos específicos etapa crisis}

- Ofrecer vías de comunicación a los familiares de las víctimas y heridos.

- Generar lazos de cercanía y empatía entre el CEO y los públicos afectados.

- Contactar a los medios de comunicación para compartir información de primera fuente.

-Actualizar la identidad corporativa de la empresa con el propósito de transmitir el sentir de la organización.

- Gestionar las redes sociales con actualizaciones constantes para informar de forma inmediata.

- Organizar espacios comunicativos en donde los colaboradores se informen acerca de la magnitud de la crisis.

- Enviar muestras de agradecimiento a los clientes habituales que siguen viajando por la aerolínea.

\subsubsection{Objetivos específicos etapa post crisis}

- Establecer políticas de prevención para gestionar futuras crisis corporativas.

- Reafirmar los atributos de seguridad y cuidado del medio ambiente ante los clientes, la prensa, los colaboradores y la comunidad. 


\section{PROPUESTA DE COMUNICACIÓN}

\section{1 Etapa crisis}

Para nuestro caso, el modelo Crisis and Emergency Risk Communication (CERC) será el referente de acción para cubrir la urgencia de la comunicación en crisis, así como la necesidad de explicar los riesgos y beneficios a las partes interesadas. Para ello se dividirá el público prioritario en interno (colaboradores) y externo (clientes, medios de comunicación, heridos, familiares de los heridos, autoridades) para informarles acerca de los acontecimientos y evitar que otros lo hagan. Siempre desde una comunicación proactiva, en donde la empresa tome las iniciativas para el acercamiento y la difusión de los contenidos.

\subsubsection{Púbico objetivo prioritario}

\section{Público objetivo Prioritario Interno}

Colaboradores: En todo momento tienen que estar enterados de los acontecimientos, además de ofrecerse como ayuda voluntaria.

\section{Público objetivo Prioritario Externo}

Heridos: Heridos llevados a los hospitales.

Familiares de las víctimas: Personas que tienen algún vínculo con las víctimas y esperan en la sala de familiares.

Medios de comunicación: Los medios esperan información de la empresa.

Clientes frecuentes: Exigen explicación de lo sucedido.

Autoridades: Colaborar con las investigaciones para determinar los responsables.

\subsubsection{Rol de los integrantes del gabinete de crisis}

El gabinete de crisis tendrá la labor de evaluar y decidir el alcance, implicaciones y tratamiento de esta.

\begin{tabular}{|c|l|}
\hline Rol & \multicolumn{1}{|c|}{ Funciones en caso de crisis } \\
\hline & Vocero autorizado ante los medios de \\
\hline
\end{tabular}




\begin{tabular}{|c|c|}
\hline Presidente Ejecutivo, CEO & comunicación, familiares, autoridades. \\
\hline $\begin{array}{l}\text { Vicepresidente } \\
\text { Entrega del Servicio al } \\
\text { Cliente }\end{array}$ & $\begin{array}{l}\text { Apoyar y coordinar los procesos } \\
\text { necesarios para la respuesta local en las } \\
\text { estaciones afectadas, garantizar la } \\
\text { activación del call center, gestión de viajes } \\
\text { para los afectados, sus familiares y } \\
\text { personal de apoyo. }\end{array}$ \\
\hline $\begin{array}{l}\text { Vicepresidente de } \\
\text { Talento Humano }\end{array}$ & $\begin{array}{l}\text { Facilitar el equipo de recursos humanos, } \\
\text { documentos y otros para la atención de la } \\
\text { emergencia. } \\
\text { Coordinar el grupo de Psicólogos para } \\
\text { tripulación y al personal de la aerolínea } \\
\text { que van que van a ir al sitio de la } \\
\text { emergencia. }\end{array}$ \\
\hline DIRC & $\begin{array}{l}\text { Coordinar, gestionar y controlar la } \\
\text { estrategia global de comunicaciones a: } \\
\text { familiares, medios de comunicación y } \\
\text { entidades gubernamentales. } \\
\text { Activación del Dark Site en coordinación } \\
\text { con el área digital y tecnología. }\end{array}$ \\
\hline $\begin{array}{c}\text { Vicepresidente } \\
\text { Administrativo y Compras }\end{array}$ & $\begin{array}{l}\text { Proveer los recursos del alto valor tales } \\
\text { como gastos funerarios, gastos de } \\
\text { hospitalización, transporte y hospedaje. } \\
\text { Facilitar la documentación o cartas de } \\
\text { garantías para la adquisición de servicios } \\
\text { o facilidades para la atención de la } \\
\text { emergencia. }\end{array}$ \\
\hline $\begin{array}{l}\text { Vicepresidente de } \\
\text { Finanzas }\end{array}$ & $\begin{array}{l}\text { Facilitar recursos financieros para atender } \\
\text { la emergencia, provee recursos necesarios } \\
\text { para gastos hospitalarios, funerarios y } \\
\text { logística de transportes. }\end{array}$ \\
\hline Vicepresidente Jurídico y legal & $\begin{array}{l}\text { Proporcionar asesoría legal con respecto } \\
\text { a los derechos y obligaciones legales de } \\
\text { la Compañía. }\end{array}$ \\
\hline
\end{tabular}


2.1.2 Plan de acción

A Continuación, se pasará a establecer las acciones específicas del plan en función a los públicos prioritarios. 


\begin{tabular}{|c|c|c|c|c|c|c|}
\hline Día & $\begin{array}{l}\text { Público } \\
\text { Objetivo }\end{array}$ & $\begin{array}{l}\text { Ideas Fuerza } \\
\text { (Mensajes) }\end{array}$ & Tono/Estilo & Acciones & Metas & Indicadores \\
\hline $10 / 06 / 19$ & Colaboradores & $\begin{array}{l}\text { "Familia los } \\
\text { necesitamos ahora } \\
\text { más que nunca" }\end{array}$ & Cálido & $\begin{array}{l}\text { Efectuar reuniones de } \\
\text { emergencia entre los } \\
\text { colaboradores para informar y } \\
\text { sensibilizar lo vivido por la } \\
\text { empresa. }\end{array}$ & $\begin{array}{l}95 \% \text { colaboradores asiste } \\
\text { a la reunión de } \\
\text { emergencia }\end{array}$ & $\begin{array}{l}\% \text { de asistencia a la } \\
\text { reunión }\end{array}$ \\
\hline $10 / 06 / 19$ & Colaboradores & $\begin{array}{l}\text { "Familia los } \\
\text { necesitamos ahora } \\
\text { más que nunca" }\end{array}$ & Huma & $\begin{array}{l}\text { Anunciar al portavoz oficial } \\
\text { de la empresa y brindarle todo } \\
\text { el apoyo de la empresa }\end{array}$ & $\begin{array}{l}\text { Anunciar } 1 \text { portavoz } \\
\text { oficial de la empresa }\end{array}$ & $\begin{array}{l}\text { Número } \\
\text { portavoces }\end{array}$ \\
\hline $10 / 06 / 19$ & $\begin{array}{l}\text { Familiares de } \\
\text { víctimas y heridos }\end{array}$ & $\begin{array}{l}\text { "Estaremos con } \\
\text { ustedes hasta el final" }\end{array}$ & Cálido y humano & $\begin{array}{l}\text { Dar inicio al call center de } \\
\text { información para familiares de }\end{array}$ & $\begin{array}{l}\text { Cubrir el } 95 \% \text { de } \\
\text { cobertura de llamadas }\end{array}$ & $\%$ de cobertura \\
\hline $10 / 06 / 19$ & $\begin{array}{l}\text { Familiares de } \\
\text { víctimas }\end{array}$ & $\begin{array}{l}\text { "Somos una gran } \\
\text { familia que tiene que } \\
\text { estar unida" }\end{array}$ & Humano & $\begin{array}{l}\text { Organizar un equipo formado } \\
\text { por más de } 100 \text { personas para } \\
\text { la atención a los familiares de } \\
\text { las víctimas con psicólogos. }\end{array}$ & $\begin{array}{l}\text { Cubrir el cupo de } 120 \\
\text { personas para atender }\end{array}$ & Cupos agotados \\
\hline
\end{tabular}




\begin{tabular}{|c|c|c|c|c|c|c|}
\hline $10 / 06 / 19$ & $\begin{array}{l}\text { Familiares de } \\
\text { víctimas }\end{array}$ & $\begin{array}{l}\text { "Estaremos con } \\
\text { ustedes hasta el final" }\end{array}$ & Cálido & $\begin{array}{l}\text { Ofrecer a las familias una } \\
\text { primera indemnización de } \\
\$ 35000 \text { por víctima. }\end{array}$ & $\begin{array}{l}\text { Pagar al 100\% la } \\
\text { indemnización a los } \\
\text { familiares de las víctimas }\end{array}$ & Pago realizado \\
\hline $10 / 06 / 19$ & Heridos & $\begin{array}{l}\text { "Nosotros asumimos } \\
\text { los gastos" }\end{array}$ & Cálido & $\begin{array}{l}\text { Cubrir los gastos de } \\
\text { hospitalización y recuperación } \\
\text { de todos los heridos }\end{array}$ & $\begin{array}{l}\text { Cubrir al } 100 \% \text { los gastos } \\
\text { hospitalarios }\end{array}$ & $\begin{array}{l}\text { Cobertura del } \\
\text { seguro }\end{array}$ \\
\hline $10 / 06 / 19$ & $\begin{array}{l}\text { Medios de } \\
\text { Comunicación }\end{array}$ & $\begin{array}{l}\text { "Tenemos una } \\
\text { trayectoria de } 24 \text { años } \\
\text { en el mercado } \\
\text { peruano" }\end{array}$ & Humano & $\begin{array}{l}\text { Elaborar un dosier de prensa } \\
\text { para informar acerca de los } 24 \\
\text { años de trayectoria de la } \\
\text { empresa }\end{array}$ & 1 dosier de prensa & $\begin{array}{l}\text { Número de dosier } \\
\text { de prensa }\end{array}$ \\
\hline $10 / 06 / 19$ & $\begin{array}{l}\text { Clientes } \\
\text { Medios de } \\
\text { Comunicación } \\
\text { Comunidad }\end{array}$ & $\begin{array}{l}\text { "Sentimos una pérdida } \\
\text { en nuestra familia" }\end{array}$ & Humano & $\begin{array}{l}\text { Cambiar el logotipo por un } \\
\text { tono gris y habilitar un dark } \\
\text { site dentro de la web con } \\
\text { información actualizada del } \\
\text { accidente. }\end{array}$ & $\begin{array}{l}6 \text { logos actualizados en } \\
\text { tono gris. } \\
1 \text { Dark site }\end{array}$ & $\begin{array}{l}\text { Logos actualizados } \\
\text { Apertura del Dark } \\
\text { site }\end{array}$ \\
\hline $10 / 06 / 19$ & $\begin{array}{l}\text { Comunidad } \\
\text { digital }\end{array}$ & $\begin{array}{l}\text { "Tenemos que estar } \\
\text { conectados en todo } \\
\text { momento" }\end{array}$ & Cálido & $\begin{array}{l}\text { Utilizar Twitter para difundir } \\
\text { sus comunicados de prensa. } \\
\text { \#Viajelindocomunica }\end{array}$ & 12 Tweets en total del día & Número de Tweets \\
\hline
\end{tabular}




\begin{tabular}{|c|c|c|c|c|c|c|}
\hline $10 / 06 / 19$ & $\begin{array}{l}\text { Comunidad } \\
\text { digital }\end{array}$ & $\begin{array}{l}\text { "Tenemos que estar } \\
\text { conectados en todo } \\
\text { momento" }\end{array}$ & & $\begin{array}{l}\text { Difundir información sobre el } \\
\text { accidente, publicar novedades } \\
\text { y preguntar preguntas en } \\
\text { Facebook. }\end{array}$ & $\begin{array}{l}6 \text { publicaciones en total } \\
\text { en Facebook } \\
500 \text { respuestas en } \\
\text { facebook }\end{array}$ & $\begin{array}{l}\text { Número } \\
\text { publicaciones }\end{array}$ \\
\hline $10 / 06 / 19$ & $\begin{array}{l}\text { Medios de } \\
\text { comunicación }\end{array}$ & $\begin{array}{l}\text { "Sentimos una pérdida } \\
\text { en nuestra familia }\end{array}$ & Humano & $\begin{array}{l}\text { Realizar rueda de prensa para } \\
\text { informar los avances y se } \\
\text { mostrase abierto a todo tipo de } \\
\text { preguntas por parte de los } \\
\text { medios de comunicación. }\end{array}$ & 1 conferencia de prensa & $\begin{array}{l}\text { Número } \\
\text { conferencias }\end{array}$ \\
\hline $10 / 06 / 19$ & $\begin{array}{l}\text { Medios de } \\
\text { comunicación }\end{array}$ & $\begin{array}{l}\text { "Le debemos una } \\
\text { explicación a la } \\
\text { sociedad" }\end{array}$ & Cálido & $\begin{array}{l}\text { Concretar una entrevista } \\
\text { exclusiva transmitida en el } \\
\text { noticiero América Noticia } \\
\text { central. }\end{array}$ & $\begin{array}{l}1 \text { entrevista exclusiva } \\
\text { con algún medio local }\end{array}$ & $\begin{array}{l}\text { Número } \\
\text { entrevistas }\end{array}$ \\
\hline $11 / 06 / 19$ & $\begin{array}{l}\text { Medios de } \\
\text { comunicación - } \\
\text { prensa televisiva }\end{array}$ & $\begin{array}{l}\text { "Sentimos una pérdida } \\
\text { en nuestra familia }\end{array}$ & Humano & $\begin{array}{l}\text { Lanzar un videocomunicado } \\
\text { explicando el sentir de la } \\
\text { empresa por parte del CEO. }\end{array}$ & $\begin{array}{l}1 \text { videocomunicado } \\
\text { lanzado por el CEO }\end{array}$ & $\begin{array}{l}\text { Número de video } \\
\text { publicado }\end{array}$ \\
\hline
\end{tabular}




\begin{tabular}{|c|c|c|c|c|c|c|}
\hline $11 / 06 / 19$ & $\begin{array}{l}\text { Medios de } \\
\text { comunicación- } \\
\text { medios radiales }\end{array}$ & $\begin{array}{l}\text { "Sentimos una pérdida } \\
\text { en nuestra familia }\end{array}$ & Humano & $\begin{array}{l}\text { Lanzar un auidocomunicado } \\
\text { de prensa explicando el sentir } \\
\text { de la empresa por parte del } \\
\text { CEO. }\end{array}$ & $\begin{array}{l}1 \text { audiocomunicado } \\
\text { lanzado por el CEO }\end{array}$ & $\begin{array}{l}\text { Número de audio } \\
\text { publicado }\end{array}$ \\
\hline $11 / 06 / 19$ & $\begin{array}{l}\text { Familiares de las } \\
\text { víctimas } \\
\text { Heridos }\end{array}$ & $\begin{array}{l}\text { "Vamos a estar juntos } \\
\text { hasta el final" }\end{array}$ & Humano & $\begin{array}{l}\text { Viaje del CEO a la ciudad de } \\
\text { Arequipa para ver a los otros } \\
\text { afectados. }\end{array}$ & $\begin{array}{l}1 \text { viaje realizado por el } \\
\text { CEO }\end{array}$ & $\begin{array}{l}\text { Número de viaje } \\
\text { realizado }\end{array}$ \\
\hline $11 / 06 / 19$ & $\begin{array}{l}\text { Clientes } \\
\text { Habituales }\end{array}$ & $\begin{array}{l}\text { "Queremos agradecer } \\
\text { su apoyo } \\
\text { incondicional hacia la } \\
\text { empresa" }\end{array}$ & Humano & $\begin{array}{l}\text { Enviar una carta a todos los } \\
\text { clientes que alguna vez usaron } \\
\text { los servicios de la aerolínea, } \\
\text { transmitiendo los duros } \\
\text { momentos que la empresa está } \\
\text { viviendo y agradecer el apoyo } \\
\text { a quienes, pese al accidente, } \\
\text { seguían viajando. }\end{array}$ & $\begin{array}{l}1 \text { carta de agradecimiento } \\
\text { elaborado por el CEO }\end{array}$ & $\begin{array}{l}\text { Número de cartas } \\
\text { realizado por el } \\
\text { CEO }\end{array}$ \\
\hline $11 / 06 / 19$ & $\begin{array}{l}\text { Medios de } \\
\text { comunicación }\end{array}$ & $\begin{array}{l}\text { "Estamos dispuestos } \\
\text { averiguar hasta el } \\
\text { final" }\end{array}$ & Humano & $\begin{array}{l}\text { Realizar rueda de prensa para } \\
\text { informar los avances del día } \\
\text { desde Arequipa. }\end{array}$ & $\begin{array}{l}1 \text { Rueda de prensa } \\
\text { realizada }\end{array}$ & $\begin{array}{l}\text { Número de rueda de } \\
\text { prensa hechas }\end{array}$ \\
\hline
\end{tabular}




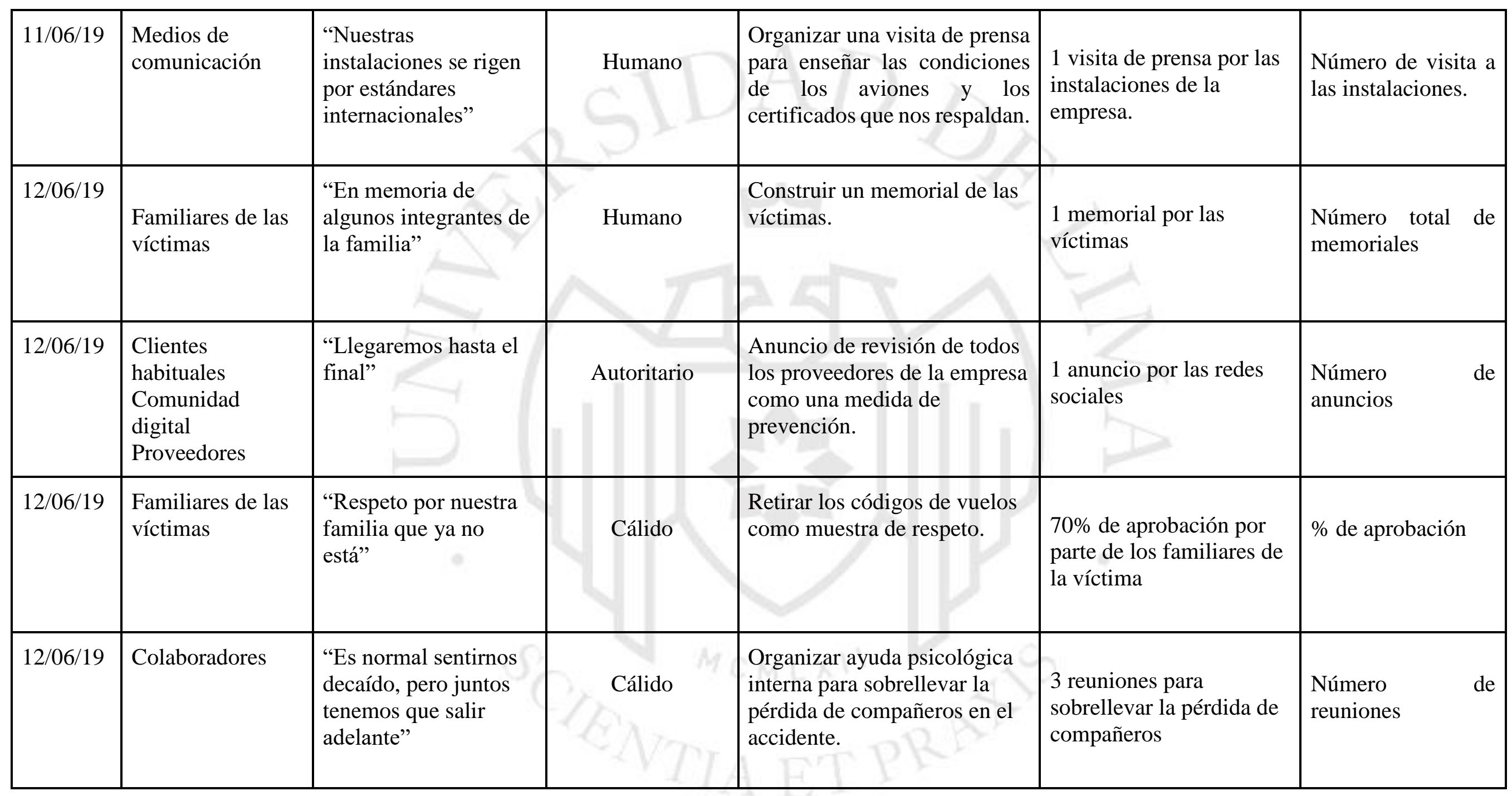




\begin{tabular}{|l|l|l|l|l|l|l|}
\hline $13 / 06 / 19$ & $\begin{array}{l}\text { Familiares de las } \\
\text { víctimas }\end{array}$ & $\begin{array}{l}\text { "Estaremos hasta el } \\
\text { final" }\end{array}$ & Humano & $\begin{array}{l}\text { Realizar varios encuentros } \\
\text { con familiares en Lima y } \\
\text { Arequipa. }\end{array}$ & $\begin{array}{l}\text { 35 encuentros entre los } \\
\text { familiares y la empresa }\end{array}$ & $\begin{array}{l}\text { Número } \\
\text { encuentros entre la } \\
\text { empresa } \\
\text { familiares } \\
\text { losectados. }\end{array}$ \\
\hline
\end{tabular}


$\underline{\text { Efectuar reuniones de emergencia entre los colaboradores para informar y sensibilizar lo }}$ vivido por la empresa

No se debe olvidar que la gestión de una crisis también involucra trabajar con los colaboradores de la empresa. Muchos de ellos quizás necesitarán ayuda psicológica para enfrentar la perdida de alguno de sus compañeros. El objetivo de estas reuniones es informarles acerca de lo sucedido y pedirles su ayuda para poder enfrentar esta crisis.

$\underline{\text { Anunciar al portavoz oficial de la empresa y brindarle todo el apoyo de la empresa }}$

Se anunciará el rol del CEO como portavoz oficial de la empresa en presencia de todos los colaboradores para simbolizar el compañerismo bajo este contexto. Posteriormente se activará unos talleres de oratoria de 45 min para trabajar la comunicación verbal y no verbal ante los medios. Temas a desarrollar: controlar la comunicación gestual, controlar el ritmo de la exposición y el tono de voz y dirigirse al periodista y no a la cámara.

$\underline{\text { Dar inicio al call center de emergencias }}$

Publicaciones

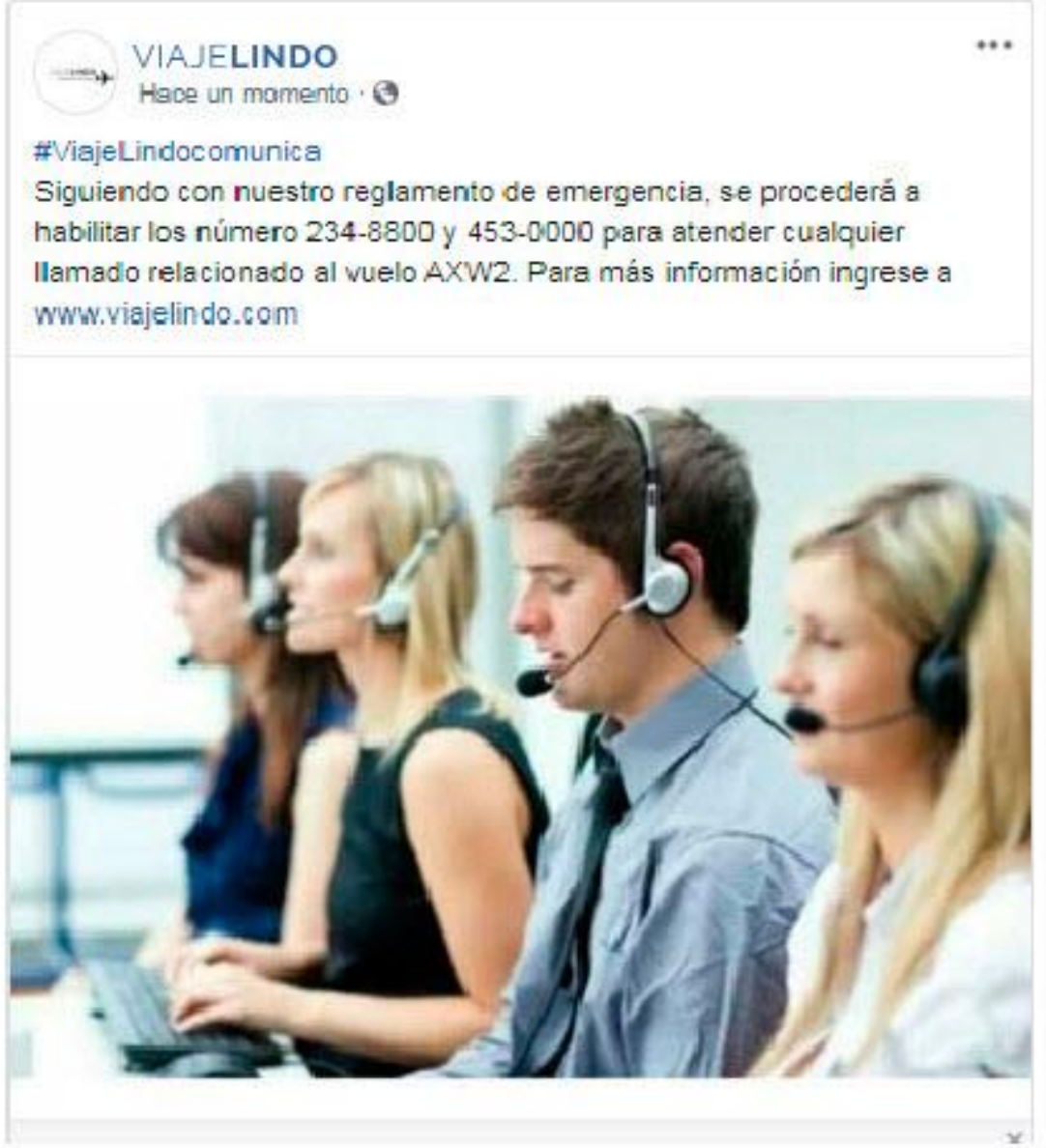


Es muy importante informar que la empresa, siguiendo con sus procedimientos de emergencia, dispondrán de número para atender dicha situación. Siempre hay que ofrecer todos los canales de comunicación al servicio del usuario, en especial a la familia de las víctimas o heridos.

\section{Organizar equipos de apoyo}

El intranet o el correo de la empresa son herramientas fundamentales para convocar a los colaboradores en los equipos de ayuda de crisis. Ellos se encargarán de atender a los familiares de las víctimas o heridos, además de representar a la empresa en este momento tan difícil. Para participar solo se tendrá que responder a la convocatoria y pasar un filtro de selección.

\section{Ofrecer a las familias una primera indemnización de $\$ 35000$ por víctima}

Se tiene que empezar a comunicar que la empresa va asumir varios costos en función a la gravedad o situación del pasajero. Esto nos permite ganar tiempo y no tener tanta exposición mediática, ni mucho menos llegar a la prensa sensacionalista.

\section{Cubrir los gastos de hospitalización y recuperación de todos los heridos}

Así como en el anterior, la empresa tiene que asumir estas responsabilidades antes que se expongan a los medios de comunicación.

\section{$\underline{\text { Elaborar el dosier de prensa }}$}

Es importante tener un documento escrito con información gráfica o audiovisual que facilite al periodista en su labor de recolección de datos. Este material tiene que ser preciso y denotar el profesionalismo de la empresa. La estructura del dosier de prensa puede contener documentos tales como: resúmenes, biografías, informes técnicos, estadísticos y legislativos. Tal como señalan Westphalen y Libaert (2009), la concepción del dosier de prensa pretende poner a disposición del periodista un medio de información práctico y de fácil acceso. 
Antes

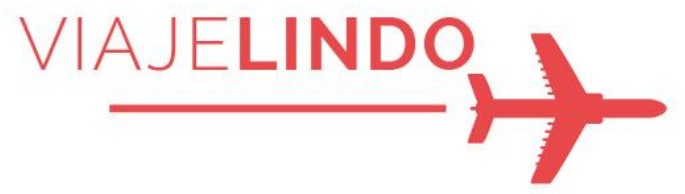

Después

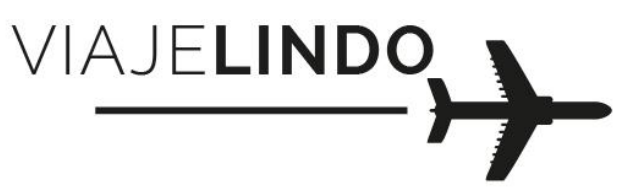

El tono cálido y humano no solo tiene que ser una característica de la comunicación verbal, ahora a través de nuestra identidad corporativa también podemos llegar a transmitir el sentir de la empresa. En todas las plataformas digitales se tendrá que hacer el cambio de color, además de activar el dark site para atendar la emergencia.

\section{$\underline{\text { Utilizar Twitter como canal para difundir sus comunicados de prensa }}$}

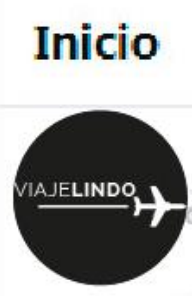

Queremos expresar nuestros más sentido pésame a todas las familias de las

víctimas del vuelo AXW2. Tenemos un gran compromiso con ustedes.

\#viajelindocomunica

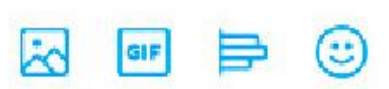

Twittear

La plataforma de Twitter es el medio oficial para que la empresa exprese sus comunicados y pensamientos más sinceros. Las otras plataformas servirán de complemento para llegar a la máxima cobertura.

Difundir información sobre el accidente, publicar novedades y hacer preguntas en Facebook.

La interacción en tiempo real es una característica demandada por los usuarios digitales, ya que ellos interactúan con la marca 24/7. Cabe mencionar que Facebook es el medio digital más usado en nuestro país y sirve mucho para crear comunidades. 
$\underline{\text { Realizar rueda de prensa para informar los avances y se mostrase abierto a todo tipo de }}$ preguntas por parte de los medios de comunicación.

Es tiempo de afrontar la segunda conferencia de prensa, para ello el CEO ha tenido una preparación en oratoria y habilidades intrapersonales. Esta vez la conferencia se resumirá en comunicar los avances del día y responder 4 preguntas de los periodistas.

\section{Concretar una entrevista exclusiva en un medio local}

Otro de los medios utilizado para difundir la información a los medios de comunicación es la entrevista exclusiva. El CEO tendrá que anunciar información de lo que la empresa está haciendo, en especial con su investigación y el reparo con las víctimas y/o familiares. En esta ocasión se está priorizando la entrevista con el noticiero América noticias edición central, ya que tiene mayor alcance y tendrá un rebote en todo el grupo El Comercio.

\section{$\underline{\text { Lanzar un videocomunicado de prensa }}$}

El video del CEO funciona muy bien si es que el mensaje llega a ser claro y directo. Siempre con un tono cálido y a veces muy humano. El objetivo es que se reflexione sobre lo ocurrido y se tenga acciones concretas para atenuar la crisis. La duración no tiene que sobrepasar los 5 minutos y el formato tendrá que ser estándar.

\section{$\underline{\text { Lanzar un audiocomunicado de prensa }}$}

Con 20 segundos de duración, el CEO anunciará el sentir de la empresa, pero sobre todo su compromiso con todos los familiares de las víctimas y heridos. Esto no será un anuncio, sino palabras de compromiso ante la sociedad.

\section{$\underline{\text { Viaje del CEO a la ciudad de Arequipa para ver a los otros afectados }}$}

Se tiene que tener presente los lugares en donde ocurrieron los hechos para así cubrirlos. El CEO viajará Arequipa para supervisar como van los avances en el otro lado de la tragedia, además de ser voluntario para atender los requerimientos de los usuarios. El mensaje es claro "Vamos a estar juntos hasta el final". 
$\underline{\text { Enviar una carta a todos los clientes que alguna vez usaron los servicios de la aerolínea }}$

Es el momento perfecto para agradecer a los usuarios que siguen viajando en la aerolínea. Por eso el correo que va ser enviado hacia ellos, tendrá que transmitir los duros momentos que la empresa está viviendo y comprometerse a solucionarlo.

\section{$\underline{\text { Realizar rueda de prensa para informar los avances del día desde Arequipa }}$}

La tercera rueda de prensa, esta vez en Arequipa, tendrán el mismo fin que la anterior. Mostrar los avances de la empresa y responder 4 preguntas de los periodistas.

\section{$\underline{\text { Organizar visita de prensa }}$}

Esta acción es muy importante para que los periodistas puedan verificar las condiciones de los aviones. Para ello se invitará a personas especializadas que comenten acerca de nuestros aviones, además de informar acerca de los estándares de calidad de la empresa.

\section{$\underline{\text { Construir un memorial de las víctimas }}$}

Como muestra de respeto se construirá un memorial de las víctimas, además de realizar una pequeña ceremonia en total privacidad. Adicionalmente, se retirará los códigos del vuelo.

Anuncio de revisión de todos los proveedores de la empresa como una medida de prevención.

Se deberá anunciar la nueva política de contratación de los proveedores como parte del aprendizaje ante esta crisis. Así la empresa se comprometerá a seguir sus estándares de calidad.

\section{$\underline{\text { Retirar el código de vuelo como muestra de respeto }}$}

La solidarización bajo estas circunstancias denota el sentir de la empresa. Por ello, el código de vuelo será retirado para conmemorar todas las víctimas. 


\section{2 Etapa post crisis}

En la etapa post crisis se priorizarán la prevención estructural para asegurar que la crisis no surja, en primer lugar, y si lo hace, que no se repita. (Wallensteen, 2002). Posteriormente, ser reafirmarán los atributos de seguridad, puntualidad y cuidado del medio ambiente.

A largo plazo, se realizará un cambio de imagen de la aerolínea que vaya acorde con las demandas del mercado actual y siga con su visión de sostenibilidad.

\begin{tabular}{|c|c|l|}
\hline P. O & Etapa & \multicolumn{1}{c|}{ Objetivo específico 1 } \\
\hline Colaboradores & Prevención & $\begin{array}{l}\text { Establecer políticas de prevención para gestionar } \\
\text { futuras crisis corporativas }\end{array}$ \\
\hline
\end{tabular}

Estrategia: Implementar políticas de prevención que tengan como eje la transparencia, la accesibilidad y difusión.

\begin{tabular}{|c|c|c|c|c|}
\hline $\begin{array}{c}\text { Ideas Fuerza } \\
\text { (Mensajes) }\end{array}$ & Tono/Estilo & Acciones & Metas & Indicadores \\
\hline $\begin{array}{l}\text { "La prevención es } \\
\text { el mejor aliado en } \\
\text { la gestión" }\end{array}$ & Cálido & $\begin{array}{l}\text { Desarrollar un } \\
\text { manual de crisis } \\
\text { para atenuar } \\
\text { situaciones } \\
\text { adversas. } \\
\text { Conformar un } \\
\text { gabinete de crisis } \\
\text { periódicamente }\end{array}$ & $\begin{array}{l}90 \% \text { de los } \\
\text { colaboradores } \\
\text { comprenda el } \\
\text { plan de crisis }\end{array}$ & $\begin{array}{l}\text { Nivel de } \\
\text { comprensión del } \\
\text { manual }\end{array}$ \\
\hline
\end{tabular}




\section{Desarrollar un manual de crisis corporativa}

El manual de crisis corporativo debe convertirse en una herramienta preventiva que contenga una guía específica y accesible para cualquier integrante que conforme el gabinete de crisis.

\section{Conformar un gabinete de crisis periódicamente.}

Se conformará el gabinete de crisis a través de las siguientes personas: CEO, vicepresidente entrega del servicio al cliente, vicepresidente de recursos humanos, DIRCOM, vicepresidente de finanzas, vicepresidente administrativo y de compras y vicepresidente jurídico y legal. Todo lo pactado será transmitido por el vocero oficial de la empresa (CEO) quién tendrá la gran responsabilidad de comunicar todos los mensajes de la organización. Se harán reuniones trimestrales para consolidar el gabinete y discutir situaciones de riesgos internos y externos reportados. Todos estos esfuerzos por defender los principios de la empresa y actuar de la mejor manera.

\begin{tabular}{|c|c|l|}
\hline P. O & Etapa & Objetivo específico 1 \\
\hline Colaboradores & Formación & $\begin{array}{l}\text { Establecer políticas de prevención para gestionar } \\
\text { futuras crisis corporativas }\end{array}$ \\
\hline
\end{tabular}

\begin{tabular}{|l|l|l|l|l|}
\hline \multicolumn{1}{|c|}{$\begin{array}{c}\text { Ideas Fuerza } \\
\text { (Mensajes) }\end{array}$} & Tono/Estilo & \multicolumn{1}{|c|}{ Acciones } & \multicolumn{1}{c|}{ Metas } & Indicadores \\
\hline $\begin{array}{l}\text { "La prevención es } \\
\text { el mejor aliado en } \\
\text { la gestión" }\end{array}$ & Cálido & $\begin{array}{l}\text { Implementar } \\
\text { talleres de } \\
\text { habilidades } \\
\text { intrapersonales } \\
\text { para los voceros }\end{array}$ & $\begin{array}{l}4 \text { talleres de } \\
\text { habilidades } \\
\text { intrapersonales }\end{array}$ & $\begin{array}{l}\text { \# talleres } \\
\text { realizados }\end{array}$ \\
\hline
\end{tabular}




\begin{tabular}{|l|l|l|l|l|}
\hline & $\begin{array}{l}\text { Implementar } \\
\text { simulacros de } \\
\text { actuación a través } \\
\text { de ejercicios } \\
\text { reales. }\end{array}$ & $\begin{array}{l}3 \text { simulacros de } \\
\text { actuación }\end{array}$ & $\begin{array}{l}\text { \# de simulacros } \\
\text { realizado }\end{array}$ \\
\hline
\end{tabular}

$\underline{\text { Implementar talleres de habilidades intrapersonales a los voceros }}$

Es muy importante que todas las personas que participan del gabinete, en especial el CEO.

Desarrollen habilidades intrapersonales para asumir situaciones de crisis de cualquier nivel. Por parte de los vicepresidentes también, ya que ellos tendrán que transmitir a sus colaboradores de la forma más asertiva. Estos talleres serán de carácter obligatorio.

\section{$\underline{\text { Implementar simulacros de actuación }}$}

Los simulacros son actos de prevención para mejorar la actuación en caso de una emergencia real. Para la aerolínea los temas más latentes son: Accidentes, aviones retrasados, interferencia ilícita, turbulencia severa, desastres naturales, disturbios civiles, crisis sociales.

\begin{tabular}{|c|c|l|}
\hline P. O & Etapa & Objetivo específico 1 \\
\hline Colaboradores & Precauciones & $\begin{array}{l}\text { Establecer políticas de prevención para gestionar } \\
\text { futuras crisis corporativas }\end{array}$ \\
\hline
\end{tabular}

\begin{tabular}{|l|l|l|l|l|}
\hline $\begin{array}{c}\text { Ideas Fuerza } \\
\text { (Mensajes) }\end{array}$ & Tono/Estilo & \multicolumn{1}{|c|}{ Acciones } & Metas & Indicadores \\
\hline $\begin{array}{l}\text { "La prevención es } \\
\text { el mejor aliado en } \\
\text { la gestión" }\end{array}$ & Cálido & $\begin{array}{l}\text { Realizar } \\
\text { auditorías que } \\
\text { permitan } \\
\text { identificar las }\end{array}$ & $\begin{array}{l}\text { 2 auditorías que } \\
\text { identifiquen las } \\
\text { vulnerabilidades }\end{array}$ & \# de auditorias \\
\hline
\end{tabular}




\begin{tabular}{|l|l|l|l|l|}
\hline & $\begin{array}{l}\text { vulnerabilidades } \\
\text { de la empresa. }\end{array}$ & de la empresa. & \\
& & & & \\
\hline
\end{tabular}

$\underline{\text { Realizar auditorias }}$

La auditoría nos ayuda a identificar posibles vulnerabilidades que están presentes en la empresa. Para este caso una auditoría interna nos ayudaría a verificar la existencia de controles internos, así como velar por el cumplimiento y proponer mejoras en el proceso.

\begin{tabular}{|c|c|c|}
\hline P. O & Etapa & \multicolumn{1}{c|}{ Objetivo específico 1 } \\
\hline Clientes & Precauciones & $\begin{array}{l}\text { Establecer políticas de prevención para gestionar } \\
\text { futuras crisis corporativas. }\end{array}$ \\
\hline
\end{tabular}

\begin{tabular}{|c|c|c|c|c|}
\hline $\begin{array}{c}\text { Ideas Fuerza } \\
\text { (Mensajes) }\end{array}$ & Tono/Estilo & Acciones & Metas & Indicadores \\
\hline $\begin{array}{l}\text { "Tu opinión nos } \\
\text { importa" }\end{array}$ & Cálido & $\begin{array}{l}\text { Realizar } \\
\text { encuestas de } \\
\text { satisfacción en } \\
\text { función a la } \\
\text { experiencia con } \\
\text { la aerolínea. }\end{array}$ & $\begin{array}{l}70 \% \text { de clientes } \\
\text { realice las } \\
\text { encuestas. }\end{array}$ & $\begin{array}{l}\text { \# de encuestas } \\
\text { realizadas }\end{array}$ \\
\hline & & $\begin{array}{l}\text { Monitorear } \\
\text { conversaciones } \\
\text { hasta encontrar }\end{array}$ & $\begin{array}{l}50 \text { insights de } \\
\text { los clientes }\end{array}$ & $\begin{array}{l}\text { \# de insights de } \\
\text { los cibernautas. }\end{array}$ \\
\hline
\end{tabular}




\begin{tabular}{|l|l|l|l|l|}
\hline & $\begin{array}{l}\text { insights. } \\
\text { Implementar un } \\
\text { botón de quejas } \\
\text { desde la app }\end{array}$ & $\begin{array}{l}\text { 200 quejas } \\
\text { desde la app }\end{array}$ & $\begin{array}{l}\text { \# de quejas de } \\
\text { los clientes. }\end{array}$ \\
\hline
\end{tabular}

$\underline{\text { Realizar encuestas de satisfacción }}$

Las encuestas de satisfacción del cliente denotan las percepciones positivas o negativas de las personas. Esto se puede dar mediante un correo electrónico o en algunos casos presencial.

\section{$\underline{\text { Monitoreo de conversaciones }}$}

Las redes sociales tienen un enorme impacto en las relaciones entre los usuarios y la empresa. La proliferación de la información y el "boca a boca" digital hace que las empresas tengan que monitorear las conversaciones de las personas para identificar posibles vulnerabilidades hacia la organización. Social mention, Google alerts, mention son algunas herramientas para realizar esta labor.

Implementar un botón de quejas desde la app

Con esta opción integrada a la app muchos usuarios compartirán sus experiencias en función a ser atendidas. El objetivo es brindarle la facilidad al usuario y la preocupación por parte de la empresa para atendar sus reclamos.

\begin{tabular}{|c|c|l|}
\hline P. O & Etapa & Objetivo específico 1 \\
\hline Proveedores & Precauciones & $\begin{array}{l}\text { Establecer políticas de prevención para } \\
\text { gestionar futuras crisis corporativas. }\end{array}$ \\
& & \\
\hline
\end{tabular}




\begin{tabular}{|l|l|l|l|l|}
\hline $\begin{array}{c}\text { Ideas Fuerza } \\
\text { (Mensajes) }\end{array}$ & Tono/Estilo & \multicolumn{1}{|c|}{ Acciones } & Metas & Indicadores \\
\hline $\begin{array}{l}\text { "Buscamos la } \\
\text { excelencia" }\end{array}$ & Serio & $\begin{array}{l}\text { Realizar nuevos } \\
\text { filtros de } \\
\text { contratación y } \\
\text { verificación de } \\
\text { proveedores. }\end{array}$ & $\begin{array}{l}\text { 3 filtros básicos } \\
\text { para contratar a } \\
\text { proveedores. }\end{array}$ & $\begin{array}{l}\text { \# de filtros } \\
\text { propuestos. }\end{array}$ \\
\hline
\end{tabular}

$\underline{\text { Realizar nuevos filtros de contratación y verificación de estado }}$

En función a la última crisis corporativa, se ha planteado restructurar los filtros de contratación de los proveedores con el propósito de reducir los riesgos de crisis. Se valorará más los ISO y/o algún otro reconocimiento que compruebe la calidad de su trabajo.

Gestión del medio ambiente (serie ISO 14000)

Gestión de Calidad (serie ISO 9000)

Gestión del medio ambiente (serie ISO 14000)

\begin{tabular}{|c|c|l|}
\hline P. O & Etapa & Objetivo específico 2 \\
\hline Colaboradores & Posicionamiento & $\begin{array}{l}\text { Reafirmar los atributos de seguridad y } \\
\text { cuidado del medio ambiente. }\end{array}$ \\
& & \\
\hline
\end{tabular}

Estrategia: Involucrar a los colaboradores con la trayectoria de la empresa reforzando los atributos de seguridad, puntualidad y cuidado del medio ambiente. 


\begin{tabular}{|c|c|c|c|c|}
\hline $\begin{array}{l}\text { Ideas Fuerza } \\
\text { (Mensajes) }\end{array}$ & Tono/Estilo & Acciones & Metas & Indicadores \\
\hline $\begin{array}{l}\text { "Somos una } \\
\text { empresa de calidad } \\
\text { que cumple los } \\
\text { estándares } \\
\text { internacionales" }\end{array}$ & $\begin{array}{l}\text { Cálido / } \\
\text { humano }\end{array}$ & $\begin{array}{l}\text { Crear una revista } \\
\text { de aniversario por } \\
\text { los } 25 \text { años de la } \\
\text { empresa } \\
\text { reafirmando su } \\
\text { trayectoria }\end{array}$ & $\begin{array}{l}1 \text { revista de } \\
\text { aniversario }\end{array}$ & $\begin{array}{l}\text { \# de revista de la } \\
\text { empresa }\end{array}$ \\
\hline . & & $\begin{array}{l}\text { línea de tiempo } \\
\text { resaltando los hits } \\
\text { de la empresa en } \\
\text { las oficinas }\end{array}$ & $\begin{array}{l}1 \text { línea de } \\
\text { tiempo en las } \\
\text { oficinas }\end{array}$ & $\begin{array}{l}\text { \# de líneas de } \\
\text { tiempo en las } \\
\text { oficinas }\end{array}$ \\
\hline $\begin{array}{l}\text { "Somos una } \\
\text { aerolínea segura } \\
\text { ante los ojos de } \\
\text { mundo" }\end{array}$ & & $\begin{array}{l}\text { Correo del CEO } \\
\text { al personal }\end{array}$ & $\begin{array}{l}90 \% \text { de los } \\
\text { colaboradores } \\
\text { administrativos } \\
\text { se informan de } \\
\text { los sucesos más } \\
\text { significativos de }\end{array}$ & $\begin{array}{l}\% \text { de } \\
\text { colaboradores se } \\
\text { informan de los } \\
\text { sucesos más } \\
\text { significativos de } \\
\text { la empresa. }\end{array}$ \\
\hline $\begin{array}{l}\text { "Queremos que } \\
\text { seas parte de esta } \\
\text { historia" }\end{array}$ & & $\begin{array}{l}\text { Reuniones de los } \\
\text { gerentes con sus } \\
\text { equipos }\end{array}$ & $\begin{array}{l}100 \% \text { de los } \\
\text { colaboradores } \\
\text { asista a las } \\
\text { reuniones. }\end{array}$ & $\begin{array}{l}\% \text { de asistencia } \\
\text { a las reuniones }\end{array}$ \\
\hline
\end{tabular}

\section{$\underline{\text { Reuniones de los gerentes con sus equipos }}$}

Una vez que los gerentes hayan entendido que los colaboradores son parte esencial de la empresa, se programarán reuniones entre los equipos de trabajo para que los colaboradores se sientan incluidos en esta celebración. El objetivo es que ellos reconozcan los atributos por los cuales la empresa se ha posicionado en la mente de las personas y los interioricen. 


\section{Correo del CEO al personal}

Este primer contacto entre el gerente general y todos sus colaboradores tendrá que transmitir un mensaje esperanzador y prometedor. El lenguaje a utilizar tendrá que denotar sencillez e involucrar a todos los colaboradores en esta celebración. Se aprovechará el intranet y el correo de la empresa para replicar este mensaje a toda la organización.

\section{Organizar una línea de tiempo con los hits más importantes}

En las oficinas de la empresa se tendrá que crear esta línea de tiempo donde se reconozcan los hitos más importantes durante estos 25 años. El objetivo es que los colaboradores identifiquen esos momentos y los interioricen.

\section{$\underline{\text { Revista de aniversario }}$}

La revista de aniversario por los 25 años de la empresa tiene que reflejar la impecable trayectoria de la organización. Se tiene que mostrar los logros, los premios, los reconocimientos y, sobre todo, el gran equipo que se tiene. Esta revista estará hecha por los colaboradores a través de sus testimonios y las fotos que ellos podrán aportar.

\begin{tabular}{|c|c|l|}
\hline P. O & Etapa & Objetivo específico 2 \\
\hline $\begin{array}{c}\text { Medios de } \\
\text { comunicación }\end{array}$ & Posicionamiento & $\begin{array}{l}\text { Reafirmar los atributos de seguridad y } \\
\text { cuidado del medio ambiente. }\end{array}$ \\
& & \\
\hline
\end{tabular}

Estrategia: Abarcar medios online y offline para reafirmar los atributos de la empresa. 


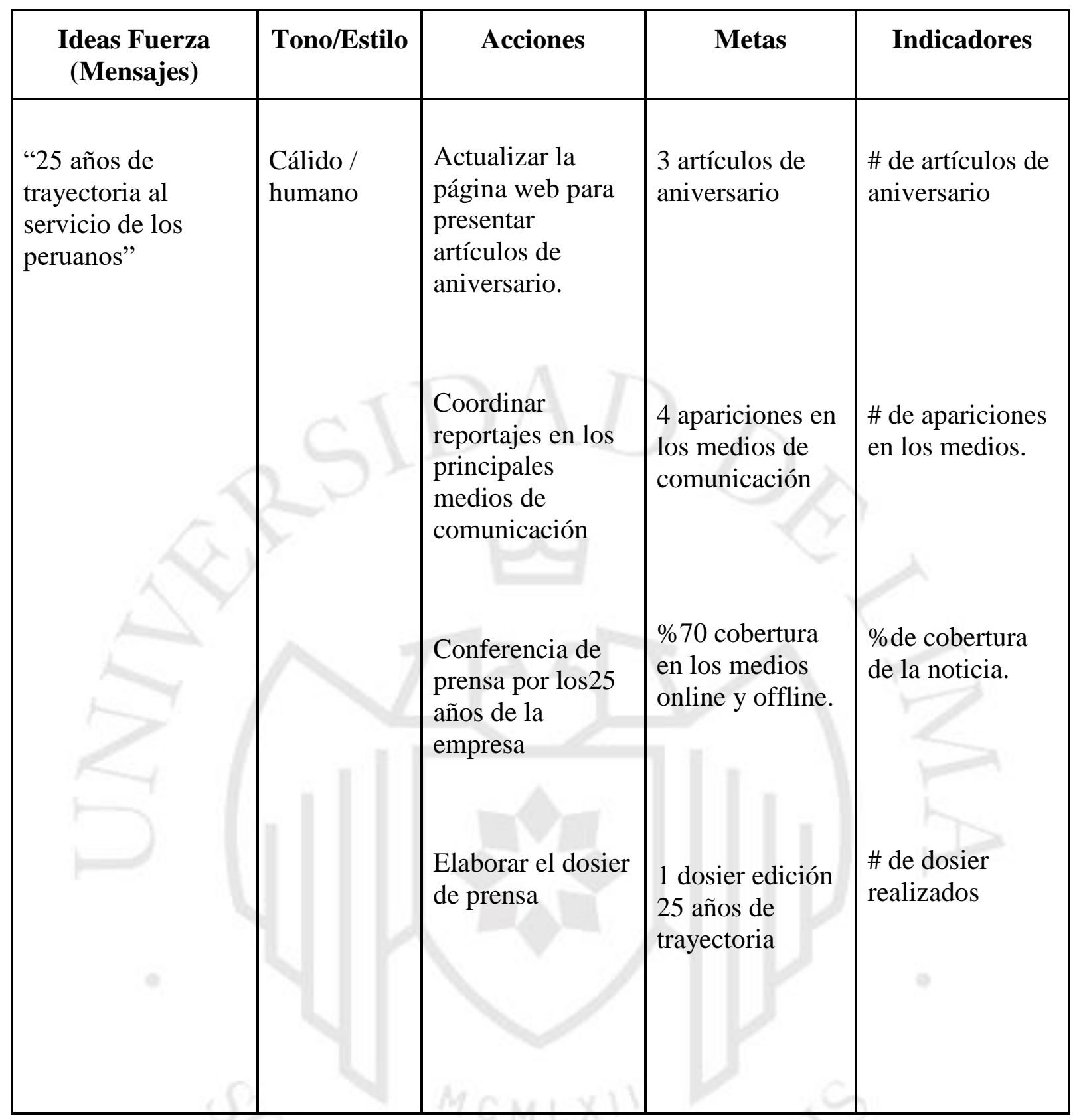

$\underline{\text { Actualizar la página web para presentar artículos de aniversario }}$

La página web es una vitrina muy importante para informar acerca de lo que es la empresa y crear un espacio más de comunicación. Por el aniversario se crearán contenidos informativos sobre los 25 años de trayectoria de la empresa, además de publicar artículos relacionado a ello. Siempre resaltando el atributo de seguridad y puntualidad como base de nuestro posicionamiento.

$\underline{\text { Coordinar reportajes en los principales medios de comunicación }}$

Se convocará a toda la red de prensa de la aerolínea para cubrir los 25 años de trayectoria 
de la empresa, además de organizar entrevistas para el CEO en los programas de Canal $\mathrm{N}$ (mundo empresarial) y RPP noticias (la rotativa del aire). Publimetro y Gestión serán los diarios donde más se invertirá para publicidad pagada.

\section{$\underline{\text { Conferencia de prensa sobre la nueva imagen }}$}

La conferencia de prensa tendrá lugar en nuestras instalaciones del aeropuerto Jorge Chávez para informar acerca de los 25 años de trayectoria de la empresa. Además de exponer las nuevas flotas de aviones que posee la empresa. Esta actividad tendrá preguntas libres por parte de los periodistas y tendrá un tiempo de duración de 30 minutos.

\section{Elaborar el dosier de prensa}

Es importante tener un documento escrito con información gráfica o audiovisual que facilite al periodista en su labor de recolección de datos. Este material tiene que ser preciso y denotar el profesionalismo de la empresa. La estructura del dosier de prensa puede contener documentos tales como: resúmenes, biografías, informes técnicos, estadísticos y legislativos. Tal como señalan Westphalen y Libaert (2009), la concepción del dosier de prensa pretende poner a disposición del periodista un medio de información práctico y de fácil acceso.

\begin{tabular}{|c|c|c|}
\hline P. O & Etapa & \multicolumn{1}{c|}{ Objetivo específico 2 } \\
\hline $\begin{array}{l}\text { Clientes } \\
\text { Comunidad }\end{array}$ & Posicionamiento & $\begin{array}{l}\text { Reafirmar los atributos de seguridad y } \\
\text { cuidado del medio ambiente. }\end{array}$ \\
Autoridades & & \\
ONG & & \\
\hline
\end{tabular}

Estrategia: Organizar actividades por los 25 años de trayectoria de la empresa en donde se refuercen los atributos de seguridad, cuidado del medio ambiente y puntualidad. 


\begin{tabular}{|c|c|c|c|c|}
\hline $\begin{array}{l}\text { Ideas Fuerza } \\
\text { (Mensajes) }\end{array}$ & Tono/Estilo & Acciones & Metas & Indicadores \\
\hline $\begin{array}{l}\text { "25 años de } \\
\text { trayectoria al } \\
\text { servicio de los } \\
\text { peruanos" }\end{array}$ & $\begin{array}{l}\text { Cálido / } \\
\text { humano }\end{array}$ & $\begin{array}{l}\text { Realizar el evento } \\
\text { día del medio } \\
\text { ambiente Viaje } \\
\text { Lindo } \\
\\
\text { Organizar el } \\
\text { taller online de } \\
\text { hábitos } \\
\text { saludables } \\
\text { impactan en } \\
\text { nuestro ambiente } \\
\text { Contratar a un } \\
\text { influencer viajero } \\
\text { para que viva el } \\
\text { buen servicio }\end{array}$ & $\begin{array}{l}70 \% \text { de } \\
\text { asistencia por } \\
\text { parte de clientes } \\
\text { habituales } \\
\text { Líderes de } \\
\text { opinión y } \\
\text { entidades } \\
\text { regulatorias } \\
\text { 50\% de } \\
\text { asistencia por } \\
\text { parte de ONG } \\
\text { asociadas y } \\
\text { líderes de } \\
\text { opinión. } \\
\\
50 \% \text { de clientes } \\
\text { habituales se } \\
\text { inscriban al } \\
\text { taller. }\end{array}$ & $\begin{array}{l}\% \text { de asistencia } \\
\text { al evento. } \\
\% \text { de clientes } \\
\text { que se inscriban } \\
\text { al taller. } \\
\text { \# de influencers } \\
\text { contratados }\end{array}$ \\
\hline
\end{tabular}

\section{$\underline{\text { Organizar el evento Vivir con menos } \mathrm{CO} 2}$}

Siguiendo con los Objetivos de Desarrollo Sostenible (ODS), nos apoyaremos del Objetivo 13: Acción por el Clima. Para desarrollar el evento Vivir con menos CO2. La empresa ha empezado por reducir su emisión de CO2 y seguirá apostando por iniciativas que lleven al cuidado del Medio ambiente. Este evento se realizará en el Country Club de Lima y será cubierto en todas las plataformas digitales. Para dicho evento se contará con la presencia de la ministra del Ambiente, Lucía Ruiz. Y la Ministra de Transporte y Comunicaciones, María Jara. Entre las líderes de opinión se destaca la presencia de 
Rosana Cueva y Sol Carreño. Se espera también la participación del presidente de la República y algunos ex congresistas de la Nación.

$\underline{\text { Realizar el evento día del medio ambiente Viaje Lindo }}$

Cada 5 de junio con la colaboración de una ONG ambientalistas aliada organizar el evento del medio ambiente. El objetivo es promover las buenas prácticas ambientales, además de disfrutar de música, comida y juegos para los más chicos. Este evento será cubierto por todas las plataformas digitales, además de emitir notas de prensa para impulsarlo.

\section{Organizar el taller online de hábitos saludables impactan en nuestro ambiente}

Para los clientes se está pensando en organizar talleres online de hábitos saludables por streaming. El objetivo es impulsar a que las personas empiecen a vivir mejor para que entiendan el significado de bienestar y nos relacionen con estas iniciativas.

\section{$\underline{\text { Contratar a influencer viajero para que vivan el buen servicio }}$}

Se convocará a los influencers: Misias pero viajeras y a Luciano Mazzetti para que vivan una experiencia en cualquiera de nuestros 8 destinos nacionales. El objetivo es que a través de ellos se evidencia los atributos de seguridad y puntualidad al momento de utilizar nuestros servicios. 


\section{SUSTENTACIÓN}

El presente trabajo de suficiencia profesional ha empezado por determinar la importancia de la gestión de los valores intangibles. Hoy en día son más las empresas que incorporan en su modelo de negocio dicha gestión para atenuar el peligro de crisis y aprovechar salir airosos. Bajo este contexto, se concluyó que el enfoque de DIRCOM aporta más valor a la organización, ya que desarrolla una visión 360 de la comunicación y la pone en función a los objetivos de la empresa.

Así, Joan Costa (2012) señala que: el Dircom es básicamente un estratega global que gestiona la comunicación empresarial y los valores intangibles de la empresa. Siguiendo con este pensamiento, el Dircom tendrá que desarrollar habilidades directivas, planificar y gestionar estrategias, dotar de sensibilidad los mensajes de alta gerencia, dirigir las comunicaciones y las relaciones con los stakeholders, velar por la responsabilidad de la imagen, la reputación y el posicionamiento corporativo, crear una cultura corporativa, fortalecer la propuesta de valor, además de gestionar crisis corporativas. Entonces ¿Qué méritos conseguirá el trabajo?

\section{1) Gestionar la crisis}

La gestión de crisis se implementará de forma inmediata tomando actitudes resolutivas, atajando la causa y actuando con hechos. El objetivo es salvaguardar la imagen y reputación de la empresa Viaje Lindo Airlines a través de acciones de comunicación que contrarresten los efectos negativos de la crisis. Además de tomar medidas preventivas que reduzcan la posibilidad de una futura crisis.

2) Mejorar el posicionamiento

Al gestionar los valores intangibles de la empresa se obtiene el posicionamiento deseado por esta. La percepción será sostenible siempre y cuando la marca mantenga su valor y cumpla su promesa. Los atributos como la puntualidad y seguridad son elementos diferenciados que ayudarán a Viaje Lindo Airlines a posicionarse en el mercado aerocomercial. Sumado a ello, se trabajará por posicionarla como una aerolínea que cuida el medio ambiente. 
3) Optimizar acciones de comunicación

Sabiendo los parámetros por el cual la empresa se rige, todas las estrategias corporativas estarán alienadas a estas y se dejará de improvisar al momento de desarrollar acciones específicas. En especial la de comunicación para que los mensajes sean decodificados de la mejor manera y se ahorre recursos de tiempo y dinero.

Por otro lado, las relaciones públicas juegan un rol importante en todo el plan de crisis, ya que abarca las relaciones con los medios de comunicación, comunidad, colaboradores y clientes. Desde esta perspectiva, las relaciones públicas constituyen el proceso de comunicación estratégica que establece e interviene en las relaciones de influencia mutua entre las organizaciones y los públicos. (Xifra,2017) 


\section{RECOMENDACIONES}

1. Seguir trabajando en la gestión de los valores intangibles, esto le permitirá a la empresa diferenciar más y prever situaciones de crisis.

2. Mantener siempre la coherencia del discurso de la empresa y su comportamiento corporativo.

3. Vivimos en tiempos hiperconectados e hipersensibles, las herramientas de comunicación tendrán que ser actualizadas bajo este contexto.

4. Hay que identificar desde un principio la naturaleza y origen de una crisis para determinar la mejor estrategia.

5. En el mapeo de stakeholders prioritarios no olvidar a los colaboradores y a los clientes frecuentes. Muchos planes descuidan esos dos grupos de intereses.

6. Mayor rapidez al atender una crisis corporativa. Mientras más tiempo pasa la credibilidad de la empresa pierde presencia.

7. Nunca mentir ante este tipo de situación. La transparencia es un valor muy apreciado por los stakeholders.

8. Ponerse en el lugar de los otros debe ser el pensamiento básico para poder atender este tipo de problemas.

9. No es lo mismo una página web que un Dark site. La primera cumple su función de vender o informar acerca del producto o servicio. Mientras que la otra es una página de comunicados. Recuerda la empresa sigue funcionando, necesita vender.

10.Nunca hacer una campaña de publicidad bajo este contexto.

11. Utilizar un lenguaje muy simple para comunicarse. 


\section{Recomendación a largo plazo para crear una nueva identidad corporativa}

Diseñar un manual de identidad que represente a la empresa en este proceso de cambio. Buscar los nuevos colores que vayan con nuestra cultura ambiental, la tipografía del represente la sencillez, pero sin dejar de ser sofisticados. Integrar elementos fotográficos en donde los colaboradores sean pieza fundamental de esta nueva cultura orientada en ellos. Para la creación de este manual se realizará entrevistas, focus groups, técnicas de proyección (herramientas cualitativas y cuantitativas).

Antes

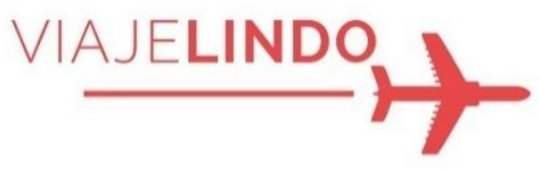

Después
VIAJE LINDO
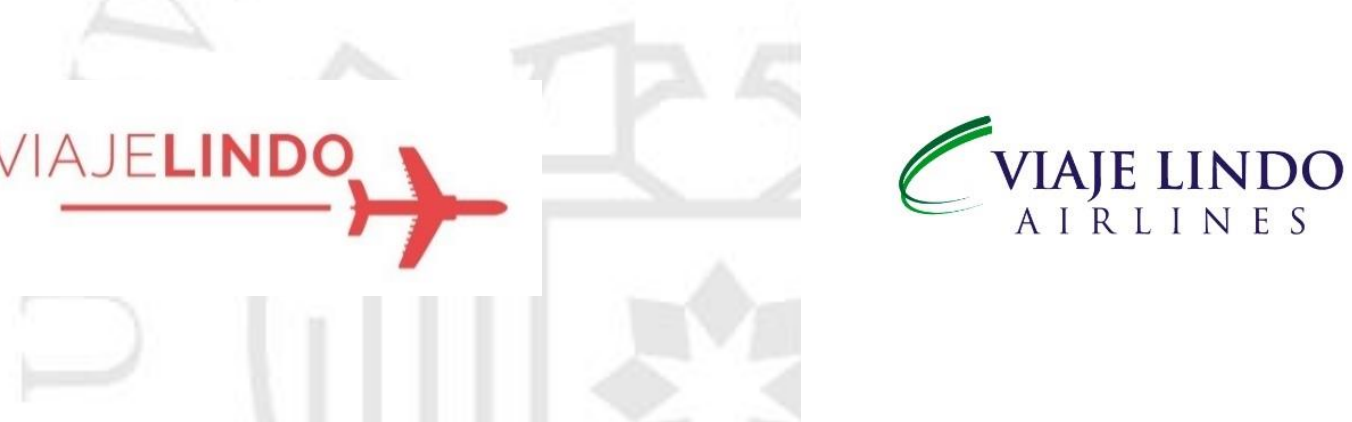

1. Atributos: Definitivamente la identidad visual actual muestra los atributos que la empresa desea posicionar. El tema del cuidado del medio ambiente se refleja en la figura semi helicoidal, además de tener el tono verde. La calidad ahora se refleja en su tipografía.

2. Logotipo/Isotipo: Se distingue del anterior, la tipografía es más elegante y los colores son de fáciles de asociar.

Isotipo: El sistema semi helicoidal denota movimiento. Esta palabra tiene mucho sentido para la empresa, ya que siempre está innovando. Además de ser elegante y simple visualmente.

Tipografía: Esta tipografía fue escogida para denotar presencia por los acabados de las letras y el peso que tiene para diferenciarse sin recurrir a lo recargado.

Colores: El verde resalta la preocupación por el cuidado del medio ambiente y el azul baya le da esa combinación perfecta para integrar armonía. 


\section{¿Bajo qué contexto se considera este cambio?}

En los últimos años el mercado de transporte aéreo en el Perú se ha proyectado a tener un crecimiento constante. Según la consultora Maximixe el tráfico aéreo de pasajeros avanzaría $8.7 \%$ este año debido al dinamismo generado en el mercado por la competencia del formato low cost y por la realización de los juegos Panamericanos (Gestión, 2019).

En el mismo informe se expresó que en el 2018 el tráfico aéreo alcanzó los 24.6 millones de pasajeros, de los cuales $51.7 \%$ corresponde a traslados al interior del país y $48.3 \%$ a entradas y salidas del país.

\section{Desarrollos en Infraestructura y rutas aéreas}

Hasta hace unos años, el transporte aéreo estaba fuertemente concentrado en Lima sin posibilidades de creer en provincia. Muchos atribuyeron que esta situación se debió a la infraestructura subdesarrollada en los aeropuertos de provincia, generando así pocas rutas disponibles. Sin embargo, con el desarrollo económico del país y el boom turístico, se tuvo que impulsar un cambio de mejora respecto al rubro aéreo.

Actualmente se viene realizando trabajos de mejora en lugares como: Piura, Chiclayo, Trujillo e Iquitos. así como la construcción de la segunda pista del aeropuerto Jorge Chávez en Lima. Al mismo tiempo, se están evaluando concesiones para un nuevo grupo de aeropuertos regionales. Estos incluyen Jaén, Jauja, Chimbote, Ilo, Huánuco, Cajamarca, Rioja y Ancash. En línea con esto, se están creando nuevas rutas aéreas tanto a nivel nacional como internacional. Entre los que destacan: Cusco - Santiago, Cusco Pisco y Cusc-Iquitos (Latam); Panamá - Chiclayo y Bogotá - Pisco- Cusco ( Avianca) ( Euromonitor, 2018)

\section{Las alternativas Low cost ganan terreno en Perú}

El término low cost cada vez más se populariza en estos tiempos, generando así un ambiente competitivo entre las aerolíneas. Personas que anteriormente viajaban de un tramo a otro en un tiempo prolongado, ahora tienen una opción más rápida, con mayor seguridad y a un costo razonable. 
Viva Air Perú y Sky Perú han sido las dos aerolíneas low cost con mayor participación en el mercado peruano. Del primero se registró un ascenso de casi más de $6 \%$ comparado al año 2018 ( 6,2\% a 12,6\%). Mientras que Sky Perú ha transportado a 51 mil pasajeros en abril y 80 mil en lo que va de Mayo del 2019. Según José Raúl Vargas, CEO de la empresa. (El comercio, 2019)

\section{Perfil del peruano viajero : Turismo interno}

Es importante conocer el perfil del turista interno, ya que las ofertas que ofrece Viaje Lindo Airlines solo disponen de vuelos nacionales hasta el momento.

Según el informe Mercado Nacional de viajes: turismo interno publicado por Promperú (2018) los jóvenes son los que más viajan, así que los centennials y millennials agrupan el $63 \%$ del total de viajeros. De este grupo $57 \%$ son mujeres, mientras que el $43 \%$ lo conforman los hombres. Sus estados civiles figuran como parte de una pareja con un $55 \%$ y el resto lo conforman las personas solteras $45 \%$. Por otro lado, el $32 \%$ viaja con amigos o familiares (ningún hijo), le sigue su grupo familiar directo con $24 \%$, en pareja $22 \%$, solo $13 \%$ y finalmente amigos o familiares (con hijos) $9 \%$.

Entre los principales aspectos al momento de elegir un destino resaltan, el 68\% escoge la naturaleza mientras que el $51 \%$ por la variedad de atractivos turísticos. Otros aspectos como la seguridad (33\%), la tranquilidad del lugar (25\%) y los servicios económicos $(22 \%)$ también influyen al momento de elegir.

Siempre los comentarios y experiencias familiares o de amistades van a servir como fuente de inspiración para viajar (44\%). El internet pasa a un segundo plano (20\%), seguidos por programas de televisión (17\%), publicidad tv (15\%) y artículos en diarios o revistas $(4 \%)$.

La mayoría de viajeros planifica su viaje al $83 \%$, entre los que no planifican el $67 \%$ es porque ya han visitado el destino antes. 
Dentro del top 5 de regiones más visitadas, Lima posee el 27\%. Le sigue Ica con $12 \%$ (entre Ica y Pisco), de ahí Piura con 8\%, finalmente Cusco y Junín con 7\% ambos. Ancash, Arequipa, La libertad, Lambayeque y Cajamarca terminan la lista.

El uso del avión crece con respecto al 2017, impulsado no solo por el NSE AB al 21\%, sino también por el NSE C con $10 \%$. Sin lugar alguna el transporte que más usan los peruanos para viajar es el bus con un $64 \%$.

Las actividades que más predomina en estos viajeros son el turismo urbano con un $83 \%$. Las personas disfrutan de visitar parque y plazas durante su estadía, además de visitar iglesias y mercados. El turismo de naturaleza representa el 56\%, de ahí viene el motivo de compras, turismo cultural, turismo de diversión.

\section{Perfil del peruano viajero digital}

Con el uso de las tecnologías, los peruanos cada vez más están afianzando su confianza en la compra por internet, ya sea por la variedad de ofertas que pueden encontrar o el ahorro en tiempo.

Según la información expuesta por el buscador de viajes KAYAK ( Infotur Latam,2017). Podemos mencionar lo siguiente:

1. El producto con mayor preferencia se lo lleva la categoría vuelo, seguido por hoteles y paquetes.

2. Entre las ciudades nacionales preferidas, además de Lima, no pueden faltar Cusco y Piura.

3. La plataforma más popular de búsqueda por el usuario peruano es la web desde su ordenador.

4. Los peruanos buscan más confort que lujos al momento de viajar. El 1\% se permite ir en clase ejecutiva, mientras que el $98 \%$ en clase económica. El 0,25\% opta por la clase económica preferente y el $0,75 \%$ restante se da un lujo viajando en primera. 
5. La mayoría de las búsquedas en la web son realizadas los días lunes y martes en horas de trabajo, entre las 11 am y las 4 pm. Los datos indican que luego de un máximo de 2 búsquedas, tardan casi lo mismo en decidirse por un hotel o un vuelo: 3 a 4 minutos.

\section{Perfil de la competencia}

A Continuación, se hará un cuadro descriptivo con respecto al mercado aéreo comercial a nivel nacional. Se ha tomado fuentes secundarias de los siguientes portales: Ministerio de Transporte y Comunicaciones, Euromonitor y las páginas propias de las aerolíneas. La recolección de datos numéricos corresponde al periodo de tiempo de enero hasta junio del 2019.

\begin{tabular}{|c|c|c|c|c|}
\hline Aerolínea & País & Categoría & Página web & $\begin{array}{c}\text { \% de tráfico } \\
\text { aéreo }\end{array}$ \\
\hline $\begin{array}{l}\text { Latam Airlines } \\
\text { Perú }\end{array}$ & Chile & $\begin{array}{l}\text { Scheduled } \\
\text { airlines }\end{array}$ & $\frac{\text { https://www.lata }}{\underline{\text { m.com/es_pe/ }}}$ & $61.86 \%$ \\
\hline $\begin{array}{l}\text { Viva Airlines } \\
\text { Perú S.A.C }\end{array}$ & España & Low cost & $\frac{\text { https://www.viva }}{\text { air.com/pe/es }}$ & $12.69 \%$ \\
\hline $\begin{array}{l}\text { Peruvian air line } \\
\text { S.A }\end{array}$ & Perú & $\begin{array}{l}\text { Scheduled } \\
\text { airlines }\end{array}$ & $\frac{\text { https://www.peru }}{\text { vian.pe/home/pe }}$ & $11.61 \%$ \\
\hline $\begin{array}{l}\text { Avianca Perú } \\
\text { S.A }\end{array}$ & Colombia & $\begin{array}{l}\text { Scheduled } \\
\text { airlines }\end{array}$ & $\frac{\text { https://www.avia }}{\underline{\text { nca.com/pe/es/ }}}$ & $5.74 \%$ \\
\hline $\begin{array}{l}\text { Sky Airline Perú } \\
\text { S.A.C }\end{array}$ & Chile & Low cost & $\frac{\text { https://www.skyai }}{\underline{\text { rline.com/peru }}}$ & $3.74 \%$ \\
\hline Star Perú & Perú & $\begin{array}{l}\text { Scheduled } \\
\text { airlines }\end{array}$ & $\begin{array}{l}\text { https://www.starp } \\
\underline{\text { eru.com/es/ }}\end{array}$ & $2.12 \%$ \\
\hline Atsa & Perú & $\begin{array}{l}\text { Scheduled } \\
\text { airlines }\end{array}$ & $\begin{array}{l}\text { https://atsaairlines } \\
. \text { com/ }\end{array}$ & $0.89 \%$ \\
\hline Musoq Wayra & Perú & $\begin{array}{l}\text { Scheduled } \\
\text { airlines }\end{array}$ & $\begin{array}{l}\text { https://wayraperu. } \\
\text { com.pe/ }\end{array}$ & $0.53 \%$ \\
\hline
\end{tabular}

\section{Factores Ambientales:}

El gran desafío en la industria: 
Todos sabemos que volar en avión no es favorable para el medio ambiente y es que en la actualidad se calcula que la aviación representa algo más del dos por ciento en las emisiones mundiales de $\mathrm{CO} 2$. En gran medida, esa es la cifra que reconoce la propia industria. (DW, 2018)

No obstante, según Stefan Gössling, profesor de las universidades suecas de Lund y Linneo y coeditor del libro 'Aviación y cambio climático: hechos, desafíos y soluciones, el $\mathrm{CO} 2$ no es el único factor por el cual deberíamos preocuparnos, sino por otras emisiones de la aviación como los óxidos de nitrógeno (NOx), el vapor del agua, las partículas, las estelas de condensación y los cambios en las nubes de cirro que tienen efectos de calentamiento adicionales.

Siguiendo con la misma línea, Gössling señala que para reducir las emisiones de carbono se tiene que trabajar en cuatro enfoques: mediante la compensación de carbono a corto plazo, el desarrollo continuo de aviones más eficientes, una mayor inversión en combustibles sostenibles (biocombustibles) y el establecimiento de rutas más respetuosas con el clima.

Finalmente, el autor hace una reflexión con respecto a las proyecciones de imagen de las aerolíneas. Para él, las campañas publicitarias denotan una imagen donde se forma parte de un grupo de personas jóvenes, urbanas, viajeros frecuentes, que visitan una ciudad diferente cada semana. Se crea una necesidad por volar aceptando todas esas ideas, sin preocuparse por el medio ambiente. 


\section{PRESUPUESTO POST- CRISIS}

Descargar el presupuesto

(https://drive.google.com/file/d/1UAEiWxD65j6GIxLDz20i9TW7nfNRsNf0/view?usp

=sharing

\begin{tabular}{|c|c|c|c|c|c|c|c|}
\hline $\begin{array}{l}\text { Realizar la creación y } \\
\text { diseño del manual de } \\
\text { identidad. }\end{array}$ & $S / 4,000$ & $\begin{array}{l}\text { Crear un mural } \\
\text { informativo }\end{array}$ & $S / 50$ & $\begin{array}{l}\text { Realizar un boletín online } \\
\text { en donde lo proveedores }\end{array}$ & $S / 250$ & $\begin{array}{c}\text { Coordinar reportajes en los } \\
\text { principales medios de } \\
\text { comunicación }\end{array}$ & $\mathrm{S} / 3,900$ \\
\hline \multirow[t]{2}{*}{$\begin{array}{c}\text { Reunión del CEO con sus } \\
\text { gerentes }\end{array}$} & \multirow[b]{2}{*}{$S / 300$} & $\begin{array}{l}\text { Evento de Ianzamiento y } \\
\text { presentación }\end{array}$ & $s / 5,500$ & $\begin{array}{l}\text { Organizar el evento Vivir } \\
\text { con menos } \mathrm{CO} 2\end{array}$ & $S / 3,000$ & $\begin{array}{l}\text { Conferencia de prensa } \\
\text { sobre la nueva imagen }\end{array}$ & $s / 2,500$ \\
\hline & & $\begin{array}{l}\text { Video del CEO hablando } \\
\text { del nuevo cambio }\end{array}$ & $S / 2,000$ & $\begin{array}{c}\text { Realizar el evento dia del } \\
\text { medio ambiente Viaje } \\
\text { lindo }\end{array}$ & $S / 1,500$ & $\begin{array}{l}\text { Desarrollar un manual de } \\
\text { crisis corporativa }\end{array}$ & S/ 5,000 \\
\hline $\begin{array}{l}\text { Reuniones de los } \\
\text { gerentes con sus } \\
\text { eauinos }\end{array}$ & $S / 300$ & \multirow{2}{*}{$\begin{array}{c}\text { Entrega souvenir } \\
\text { brandeados con la nueva } \\
\text { imagen }\end{array}$} & & \multirow{2}{*}{$\begin{array}{c}\text { Organizar el taller online } \\
\text { de hábitos saludables }\end{array}$} & & \multirow{4}{*}{$\begin{array}{c}\text { Implementar talleres de } \\
\text { habilidades } \\
\text { intrapersonales a los } \\
\text { voceros }\end{array}$} & \multirow[b]{4}{*}{$\mathrm{S} / 3,250$} \\
\hline \multirow{2}{*}{$\begin{array}{c}\begin{array}{c}\text { Crear jalavistas colgado y } \\
\text { wallpapers }\end{array} \\
\end{array}$} & \multirow{3}{*}{ S/ $2,000 \mid$} & & \multirow{3}{*}{ S/ 350} & & $S / 450$ & & \\
\hline & & \multirow{2}{*}{ Premio "En hora buena } & & \multirow{2}{*}{$\begin{array}{c}\text { Actualizar la pagina web } \\
\text { para presentar la nueva } \\
\text { imaden }\end{array}$} & \multirow{2}{*}{$S / 300$} & & \\
\hline frasco pequeño Invitaciór & & & & & & & \\
\hline & & & & & & $S / 40$, & \\
\hline
\end{tabular}

\section{CRONOGRAMA}

Descargar el cronograma

(https://drive.google.com/file/d/1UAEiWxD65j6GIxLDz20i9TW7nfNRsNf0/view?usp =sharing

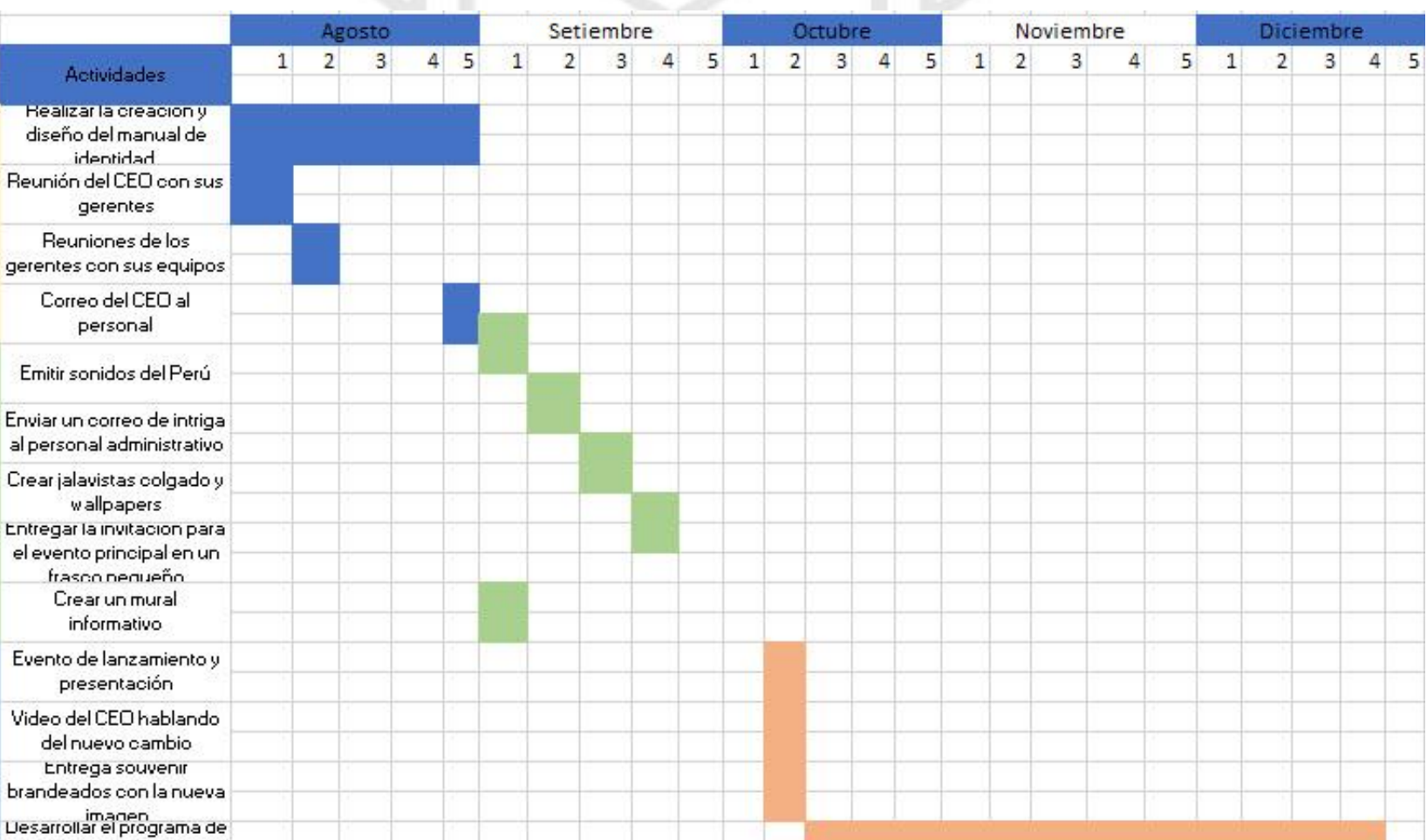




\section{REFERENCIAS}

Escobar, J. M., \& Gómez, M. (2015). Diálogos con los DIRCOM: Conceptualizaciones, casos y expertos.

López, M. J. (2018). SOS: 25 casos para superar una crisis de reputación digital.

Moles, A. A., \& Costa, J. (2010). La Comunicación: 10 voces esenciales. Barcelona: Costa Punto Com.

U.S. Department of Health and Human services (2014). Crisis Emergency + Risk Communication. Recuperado de: https://emergency.cdc.gov/cerc/resources/pdf/cerc_2014edition.pdf

Informe Aéreo (2019). Preocupa baja rentabilidad de la industria aérea en Latinoamérica. Recuperado de:

http://informeaereo.com/2019/06/preocupa-baja-rentabilidad-de-la-industria-aerea-enlatinoamerica/

BBC (2019). Cuáles son las rutas aéreas que más ingresos generan a las aerolíneas. Recuperado de:

https://www.bbc.com/mundo/noticias-49339277

Hosteltur (2019). Iberia tiene la ruta aérea más rentable de América Latina.

Recuperado de:

https://www.hosteltur.com/lat/130631_iberia-tiene-la-ruta-aerea-mas-rentable-deamerica-latina.html

AMADEUS (2015).Future traveller tribes 2030, Understanding tomorrow's traveler. Recuperado de: https://amadeus.com/documents/en/retail-travel-agencies/research$\underline{\text { report/amadeus-future-traveller-tribes-2030-report.pdf?crt=DownloadRequest }}$

Comunicae (2018) El Turista: Ese perfil con cientos de semejanzas y miles de diferencia 
Recuperado de: https://www.comunicae.es/nota/el-turista-ese-perfil-con-cientos-de$\underline{1197445 /}$

DW (2018). ¿Volar o no volar? El coste medioambiental del transporte aéreo

Recuperado de: https://www.dw.com/es/volar-o-no-volar-el-coste-medioambientaldel-transporte-aéreo/a-42096313

Armosfair (2018). Armosfair Airline Index. Recuperado de:https://www.atmosfair.de/wp-content/uploads/aai2018-englischsw.pdf

Gestión (2019). Transporte aéreo de pasajeros crecerá $8.7 \%$ por el dinamismo del mercado low cost. Recuperado de:https://gestion.pe/economia/transporte-aereopasajeros-crecera-8-7-dinamismo-mercado-low-cost-263707-noticia/

Euromonitor (2018). Airlines in Peru. Recuperado de: file:///C:/Users/PC_0000114/Downloads/Airlines_in_Peru\%20(3).pdf

El Comercio (2019). Aerolíneas: Se reconfigura el rankíng de las líderes ante boom de las low cost. Recuperado de:

https://elcomercio.pe/economia/dia-1/aerolineas-reconfigura-ranking-lideres-boomlow-cost-latam-avianca-viva-air-sky-airline-noticia-634694

PromPerú (2018). Perfil del vacacionista Nacional 2018. Recuperado de: https://www.promperu.gob.pe/TurismoIN/sitio/VisorDocumentos?titulo=Perfil\%20del \%20Vacacionista\%20Nacional\%202018\&url= /Uploads/perfiles_vacac_nac/1040/Perfi 1\%20de1\%20Vacacionista\%20Nacional\%202018.pdf\&nombObjeto=PerfVacacionistaN $\underline{\text { ac\&back=/TurismoIN/sitio/PerfVacacionistaNac\&issuuid }=}$

Infotur Latam (2017). Kayak presenta el perfil del viajero digital peruano. Recuperado de: $\quad$ https://www.infoturperu.com.pe/index.php/empresa/item/171-kayak-presenta-elperfil-del-viajero-digital-peruano 
Ministerio de Transporte y Comunicaciones (2019). Perú: Tráfico Mensual de pasajeros a nivel nacional según líneas aéreas. Recuperado de:

https://portal.mtc.gob.pe/transportes/aeronautica_civil/estadistica/documentos/2019_PD F/agosto/pasajeros/P4_tra_men_pax_cia_nac_2019.pdf

Logic activity (2015) Un análisis de la gestión de crisis en los últimas 15 años. Recuperado de :https://logicactivity.com/wpcontent/uploads/GestiondeCrisisAerolineas_Nov2015.pdf

El Mundo (2014). El avión de Air Algerie perdió altitud rápidamente antes de entrar en la tormenta. Recuperado de:

https://www.elmundo.es/internacional/2014/07/30/53d90a28e2704e14488b458d.html

El País (2015). Germanwings, una tragedia en siete actos que consternó al mundo. Recuperado de:

https://elpais.com/internacional/2015/04/23/actualidad/1429779550_951501.html

El Mundo (2014). Un fallo mecánico causó el accidente de AirAsia en el que murieron 162 pasajeros. Recuperado de: https://www.elmundo.es/internacional/2015/12/01/565d589eca4741037f8b45c1.html

El Comercio (2019). ¿Qué sucedió con el vuelo MH370 de Malaysia Airlines? Un estudio periodístico intenta revelar el misterio. Recuperado de:

https://www.elcomercio.com/actualidad/estudio-vuelo-mh370-malaysiadesaparecido.html

Coombs y Holladay (2012) Comunicación de crisis, redes sociales y reputación corporativa. ESIC 
Clarín (2019). Murieron 228 personas. Absuelven a Airbus y Air France por el accidente del vuelo Río- París en 2009. Recuperado de: https://www.clarin.com/mundo/absuelvenair-bus-air-france-accidente-vuelo-rio-paris-2009_0_NzfqBr6DF.html

Euprera (2018). European Comunication Monitor. Recuperado de: http://www.communicationmonitor.eu/

Informe de la relación dircom- periodistas (2012).Dircom. Recuperado de: http://www.dircom.org/images/stories/news/Noticias/ActualidadDircom/documento\%2 0entrega\%20estudio\%20asistentes.pdf

Xifra, J. (2017). Manual de relaciones públicas e institucionales. Madrid: Tecnos. 